\title{
Comparative Adsorptive Removal of Selected Heavy Metals from Battery Wastewater by Purified and Polyethylene Glycol Modified Carbon Nanotubes
}

\section{Abdulkareem AS}

Federal University of Technology Minna

Hamzat WA

Federal University of Technology Minna

Tijani JO

Federal University of Technology Minna

\section{Bankole MT}

Federal University of Technology Minna

Titus Egbosiuba ( $\nabla$ egbosiubachinedu@gmail.com )

Chukwuemeka Odumegwu Ojukwu University https://orcid.org/0000-0003-4402-5405

Abubakre OK

Federal University of Technology Minna

S Mustapha

Federal University of Technology Minna

\section{Research Article}

Keywords: Heavy metals, Carbon nanotubes, Polyethylene glycol, Battery industrial wastewater, Adsorption technology

Posted Date: April 16th, 2021

DOl: https://doi.org/10.21203/rs.3.rs-374698/v1

License: (a) (1) This work is licensed under a Creative Commons Attribution 4.0 International License. Read Full License 


\title{
Comparative Adsorptive Removal of Selected Heavy Metals from Battery Wastewater by Purified and Polyethylene Glycol Modified Carbon Nanotubes
}

\author{
Abdulkareem AS ${ }^{1,2}$, Hamzat $\mathrm{WA}^{2}$, *Tijani $\mathrm{JO}^{1,3}$, Bankole $\mathrm{MT}^{1,3}$, Egbosiuba $\mathrm{TC}^{1,2,5^{*}}$, \\ Abubakre $\mathrm{OK}^{4}$, Mustapha $\mathrm{S}^{1,3}$ \\ ${ }^{I}$ Nanotechnology Research Group, African Centre for Excellence on Mycotoxin, Federal \\ University of Technology, P.M.B 65, Bosso, Minna, Niger State, Nigeria. \\ ${ }^{2}$ Department of Chemical Engineering, Federal University of Technology, P.M.B 65, Gidan \\ Kwano, Minna, Niger State, Nigeria. \\ ${ }^{3}$ Department of Chemistry, Federal University of Technology, P.M.B 65, Bosso, Minna, Niger \\ State, Nigeria. \\ ${ }^{4}$ Department of Mechanical Engineering, Federal University of Technology, P.M.B 65, Gidan \\ Kwano, Minna, Niger State, Nigeria. \\ ${ }^{5}$ Department of Chemical Engineering, Chukwuemeka Odumegwu Ojukwu University, Uli \\ Anambra State, Nigeria.
}

Corresponding Author: Titus Chinedu Egbosiuba

Department of Chemical Engineering, Chukwuemeka Odumegwu Ojukwu University, PMB 02, Uli, Anambra State, Nigeria.

E-mail address: egbosiubachinedu@gmail.com,ct.egbosiuba@coou.edu.ng. 


\begin{abstract}
Comparative adsorption study of some toxic metals ( $\mathrm{Ni}, \mathrm{Fe}, \mathrm{Cu}, \mathrm{Cd}$, and $\mathrm{Pb}$ ) from battery industrial effluent by purified and polyethylene glycol-modified carbon nanotubes (CNTs) is reported. The as-prepared CNTs via chemical vapour deposition method (A-CNTs), its acid purified form (PCNTs), and polyethylene glycol functionalized form (PEG-CNTs) were characterized by HRTEM, BET, HRSEM, FTIR and XRD. The HRSEM and HRTEM micrograph revealed the formation of multi-walled tubular network structures of different inner and outer diameter. The BET study of PEG-CNTs and purified CNTs showed surface areas of $970.81 \mathrm{~m}^{2} / \mathrm{g}$ and $781.88 \mathrm{~m}^{2} / \mathrm{g}$, respectively. The nanomaterials batch adsorption effect of various parameters such as contact time, nanoadsorbent dosage and temperature was conducted. The optimum equilibrium to achieve maximum removal of $\mathrm{Cd}(83.41 \%), \mathrm{Ni}(92.79 \%)$, Fe (95.93\%), Pb (97.16 \%) Cu (99.9 9\%) using PEGCNTs was 90 min of contact time, $0.3 \mathrm{~g}$ of nano-adsorbent dosage and $60{ }^{\circ} \mathrm{C}$ temperature. While the maximum percentage removal efficiencies accomplished using P-CNTs under the same applied conditions were $\mathrm{Cd}$ (78.64 \%), Ni (76.12\%), Fe (92.87\%), Pb (90.7 2\%) Cu (99.09 \%). PEGCNTs was seen as more effective than P-CNTs. Adsorption data of Ni on P-CNTs followed Langmuir isotherm while the adsorption equilibrium model (Freundlich isotherm) of $\mathrm{Ni}, \mathrm{Fe}, \mathrm{Cu}$ and $\mathrm{Pb}$ on PEG-CNTs were fitted well. However, in both cases, the sorption kinetic study followed the pseudo-second-order model. The thermodynamics showed that the removal of toxic metals from battery wastewater was spontaneous and endothermic irrespective of the nano-adsorbents. The study found that surface modification of CNTs by polyethylene glycol adequately improved the nanotubes, thus leading to relatively adsorption capacities of heavy metals from industrial battery effluent.
\end{abstract}

Keywords: Heavy metals, Carbon nanotubes, Polyethylene glycol, Battery industrial wastewater, Adsorption technology. 


\section{Introduction}

The modern trend of the water shortage is worrisome, related to projection by World Bank and World Health Organization (WHO) that come 2025 not fewer than three billion populaces globally will not have access to clean water (Bankole et al., 2019). The decline and deterioration of limited water resources have been primarily caused by pollutants like heavy metals, organic bacteria, viruses, microcystins and antibiotics discharged through anthropogenic activities into water bodies (Xiangtao et al., 2012 and Egbosiuba et al., 2020a). Heavy metals are highly toxic and mainly originate from the electroplating, printing, painting, dyeing, clothing, mining, and battery manufacturing industries in high quantities in water bodies. They are acquired through the food chain and cause danger to human and aquatic organisms (Yuanyuan et al., 2014). Due to the released of high concentrations of heavy metals into the environment, there have been several reports of health hazard to aquatic and living organisms (Egbosiuba et al., 2020b and Igwegbe et al., 2020). For example, high concentrations of zinc lead to skin diseases, vomiting, stomach cramps, nausea and anaemia, excessive ingestion of copper causes severe toxicological problems like vomiting, seizure of breath, cramps or even death (Aamir et al., 2016), and excessive intake of nickel into human bodies may lead to lung and kidney dysfunction, gastrointestinal disorders, and gastrointestinal disease. High mercury consumption in the living organism also causes damage to the central nervous system and dysfunction of pulmonary function, kidney function and chest pain (Fengilanet al., 2010). Similar or worse negative impacts of lead, cadmium and chromium have been identified on aquatic and human species (Jiaxing et al., 2011; Chungsying et al., 2016).

Researchers have applied various chemical/physical methods for the removal/elimination of toxic metals from both simulated and industrial wastewater (Egbosiuba et al., 2021a; El-Nemr et al., 2020; El-Enein et al., 2020). These methods include reverse osmosis (Al-Obaidi et al., 2017), 
flocculation and coagulation (GilPavas et al., 2017), precipitation (Prazeres et al., 2020), extraction of solvents (Zhang et al., 2020), exchange of ions (Ma et al., 2019), ozonation (Zhan et al., 2019) and electrolysis ( $\mathrm{Li}$ et al., 2017). However, similar to these methods, the process of adsorption is considered most suitable as a result of its significant merits which include efficiency, simplicity, low cost and profitability (Egbosiuba et al., 2021b; Mudzielwana et al., 2019; Salih and Ghosh, 2018). The adsorption technique is not only versatile but also effective in eliminating hazardous and harmful contaminants even at trace levels (Rao and Kashifuddin, 2012).

Researchers have extensively studied quite a range of adsorbents prepared from readily available and low-cost materials for the sequestering of toxic metals from aqueous phase solution. Materials like chitosan (Xiangtao et al., 2012), and agricultural wastes (Ozsin et al., 2019; Rahmani-Sani et al., 2019; Jankovic et al., 2019) have shown promising results in removing heavy metals but suffered from low adsorption power, low efficiency and a high time consumption rate. Carbon nanomaterials, notably carbon nanotubes (CNTs), have offered better and convincing advantages when removing heavy metals (Bankole et al., 2019). Due to their extraordinary and unique mechanical, thermal, electrical and optical properties, comprehensive studies have been performed over nearly three decades on CNTs synthesis, properties, and applications in different areas (Mohammed et al., 2016). Because of their unique properties, CNTs have been widely integrated into polymers to form composites deemed useful in drug delivery vehicles, gene therapy, wastewater treatment, to name but a few (Sharmeen et al., 2018). For instance, when modified with compounds which have the desired functionalities, CNTs have been found to have significant improvements in high adsorption capacity (Bankole et al., 2019). Suffice it to mention that, during synthesis, CNTs normally aggregate and as such affect their adsorptive performance during application. One such modifier used in this study is polyethylene glycol (PEG) to reduce the extent 
of agglomeration. Polyethylene glycol (PEG) is a viscous liquid which is colourless, odourless, non-volatile and oligomeric. In addition, PEG is also classified as a hydrophilic molecule because of the presence of electron donor hydroxyl groups $(\mathrm{OH})$ which react in solution with hydrophobic compounds.

PEG possesses excellent moisture retaining capacity, good thermal stability, and good flexibility. The remarkable properties of polyethylene glycol functionalized carbon nanotubes have been employed widely for drug delivery (Bottini et al., 2011; Sacchetti et al., 2014; Sharmeen et al., 2018). Not only that CNTs alone have been used to remove diverse organic and inorganic contaminants from simulated and industrial wastewater as reported by Huang et al. (2015), Farghali et al. (2017) and Mohammed et al. (2014). Very recently, our research group demonstrated successful removal of $\mathrm{Cr}$ and $\mathrm{Zn}$ from electroplating wastewater by purified and polyethylene glycol functionalized multi-walled carbon nanotubes (Hamzat et al. 2019). The authors found that highest removal rate of $\mathrm{Cr}$ (contact time, $90 \mathrm{~min}$ ) and $\mathrm{Zn}$ (contact time, $50 \mathrm{~min}$ ) at adsorbent dosage $(0.3 \mathrm{~g})$ by P-CNTs and PEG-CNTs, respectively were achieved. Thus, there is need to buttress the removal of other toxic metals likely to be present in the industrial wastewater.

To the best of our understanding, this study reports for the first time the optimization and comparative adsorption study of purified carbon nanotubes (P-CNTs) and polyethylene glycol functionalized carbon nanotubes (PEG-CNTs) for the removal of selected heavy metals (Ni, Fe, $\mathrm{Cu}, \mathrm{Cd}$, and $\mathrm{Pb}$ ) from battery industrial wastewater. Firstly, synthesis of carbon nanotubes by chemical vapour deposition (CVD) of acetylene gas at a flow rate $(200-300 \mathrm{ml} / \mathrm{min})$, reaction temperatures $\left(750-800{ }^{\circ} \mathrm{C}\right)$, reaction time $(45-60 \mathrm{~min})$, Argon flow rate $(100-300 \mathrm{ml} / \mathrm{min})$ onto $\mathrm{Fe}-$ $\mathrm{Ni} /$ kaolin catalyst/support prepared by wet impregnation technique were investigated. Secondly, 
the prepared carbon nanotubes were purified with $\mathrm{H}_{2} \mathrm{SO}_{4} / \mathrm{HNO}_{3}$ mixture and subsequently functionalized with polyethylene glycol. The carbon nanostructures were characterized using different analytical techniques and batch adsorption behaviour of the purified and functionalized CNTs for heavy metal removal from battery industrial wastewater.

\section{Materials and Methods}

\subsection{Materials}

The analytical grade chemicals/reagents used in this study were obtained from Sigma Aldrich, namely: nickel(II) trioxonitrate (V) hexahydrate, trioxonitrate(V) nonahydrate, polyethylene glycol (PEG), dimethylformamide (DMF), hydrogen tetraoxosulphate (VI) and trioxonitrate (V) acid with a purity percentage of 95.5-99.9\%. The British Oxygen Company, Nigeria supplied liquid nitrogen, nitrogen gases, acetylene, and argon gas.

\subsection{Synthesis of Fe-Ni/kaolin catalyst}

The preparation of bimetallic Fe-Ni catalyst assisted on kaolin using wet impregnation method was employed. The bimetallic catalyst (Fe-Ni/kaolin) was synthesized using the same weight percentage of Fe (3.64 g salt) and Ni (5.05 g salt) followed by kaolin (8 g) was weighed into 250 $\mathrm{cm}^{3}$ beaker, accompanied by $50 \mathrm{~cm}^{3}$ of distilled water to form a slurry. The mixture was continuously stirred at $500 \mathrm{rpm}$ for $6 \mathrm{~h}$ on a magnetic stirrer and later allowed to age overnight. The sample was then dried for $8 \mathrm{~h}$ and later ground at a temperature of $120^{\circ} \mathrm{C}$ and calcinated for $14 \mathrm{~h}$ in the furnace at $400{ }^{\circ} \mathrm{C}$. The powder sample was sieved through a mesh size of $150 \mu \mathrm{m}$ after cooled to room temperature.

\subsection{Production of carbon nanotubes}

The CNTs were produced on $1.0 \mathrm{~g}$ of the as-prepared bimetallic Fe-Ni/kaolin catalyst in a quartz crucible by the decomposition of acetylene $\left(\mathrm{C}_{2} \mathrm{H}_{2}\right)$ in a chemical vapour deposition (CVD) furnace. 
Parametric studies in the synthesis of CNTs investigated the effect of argon flow rate (100-300 $\mathrm{ml} / \mathrm{min})$, reaction temperature $\left(750-800^{\circ} \mathrm{C}\right)$, reaction time $(45-60 \mathrm{~min})$, argon flow rate $(100-300$ $\mathrm{ml} / \mathrm{min}$ ) and acetylene flow rate $(200-300 \mathrm{ml} / \mathrm{min})$ on the CNT yield as shown in Table 1 .

Table 1: Variation of parameters for the $2^{4}$ factorial designs for CNTs syntheses

\begin{tabular}{lcccc}
\hline Variables & Reaction & Reaction Time & ArFlowrate & $\mathrm{C}_{2} \mathrm{H}_{2}$ Flowrate \\
& Temp. $\left({ }^{\circ} \mathrm{C}\right)$ & $(\mathrm{min})$ & $(\mathrm{ml} / \mathrm{min})$ & $(\mathrm{ml} / \mathrm{min})$ \\
\hline Low level (-) & 750 & 45 & 100 & 200 \\
High level (+) & 800 & 60 & 300 & 300 \\
\hline
\end{tabular}

The yield of CNTs (\%) obtained was studied using Equ. 1 as follows:

$$
\text { CNTs Yield (\%) }=\frac{\mathrm{W}_{\text {Product }}-\mathrm{W}_{\text {catalyst }}}{\mathrm{W}_{\text {catalyst }}} \times 100 \%
$$

where $\mathrm{W}_{\text {Product }}$ and $\mathrm{W}_{\text {catalyst }}$ are the total mass of the catalyst and final carbon products after the CVD reaction method and initial mass of $\mathrm{Fe}-\mathrm{Ni} / \mathrm{kaolin}$ catalyst, respectively.

\subsection{Purification and functionalization of CNTs}

The as-synthesized CNTs (A-CNTs) were treated with $30 \% / w t$ of concentrated nitric and sulphuric acid (v/v 1:3), stirred and sonicated at a temperature of $40^{\circ} \mathrm{C}$ for 90 minutes using ultrasonic baths to remove impurities and introduction of oxygen group to the CNTs surface. The mixture was copiously washed with de-ionized water and filtered to attain the $\mathrm{pH}$ 7. This was followed by filtering and the residue was oven-dried at $120 \mathrm{oC}$ for $12 \mathrm{~h}$ to give purified CNTs (PCNTs). The P-CNTs were functionalized with $10 \%$ Polyethylene glycol (PEG) solution. $5.0 \mathrm{~g}$ of P-CNTs was dispersed under the fume cupboard in a known volume of anhydrous DMF and afterwards, the resulting mixture was stirred at $25{ }^{\circ} \mathrm{C}$ for $18 \mathrm{~h}$ and further centrifuged for 10 minutes. The resultant sample (black solid residue) was washed with de-ionized water after 
centrifugation until the $\mathrm{pH}$ of 7 was obtained. The PEG-functionalized CNT (PEG-CNTs) was dried for $12 \mathrm{~h}$ at $120^{\circ} \mathrm{C}$.

\subsection{Characterisation of carbon nanotubes}

The as-synthesised-CNTs, P-CNTs, and PEG-CNTs obtained at optimum conditions were characterised using thermogravimetric analysis (TGA), High-Resolution scanning microscopy (HRSEM), High-Resolution transmission electron microscopy (HRTEM), Brunauer Emmett

Teller (BET), Fourier transform infrared spectroscopy (FTIR), X-ray diffraction (XRD) and electron dispersion spectroscopy (EDX). The thermal stability of samples was examined using TGA (Perkin Elmer, USA). The X-ray diffraction analysis was investigated on the samples using a Buker AXS D8 diffractometer. The diffractometer was equipped with a $\mathrm{Cu} \mathrm{K} \alpha$ radiation source which functions in the range of $10-90^{\circ}$. The surface area and porosity were achieved using Sorptometric 1990 Thermo Fisher Scientific Inc BET model. The particle size was examined by Zeiss Auriga HRTEM coupled with EDS and morphology was analysed by Zeiss Auriga HRSEM at operating condition of a $5 \mathrm{kV}$. The functional groups were performed using a Perkin Elmer spectrum FTIR spectrometer, USA. The spectra recorded for the samples are in the range from 4000 to $500 \mathrm{~cm}^{-1}$.

\subsection{Analysis of battery industrial wastewater}

The battery industrial wastewater was collected in a clean plastic container of 50 litres from a battery company located in Ilorin, Kwara State, Nigeria. The wastewater was transported to the Laboratory and all analyzes were carried out to determine the physical-chemical parameters according to the procedure reported by the American Public Health Association (APHA, 2012). Electrical conductivity and wastewater $\mathrm{pH}$ were measured using a multi-parameter analyser C3010. Fluoride was also determined using HACH, USA instruments. Dissolved oxygen (DO) 
was determined using $\mathrm{DO}_{2}$ Meter. Also calculated parameters were total dissolved solids (TDS), biochemical oxygen demand (BOD), chemical oxygen (COD), sulphate, phosphate, ammonium, nitrate, nitrite, chloride and cyanide in the wastewater. These analyses were carried out at Federal Ministry of Water Resources, Regional Water Quality Laboratory, Minna, Nigeria. The concentration in $\mathrm{mg} / \mathrm{dm}^{3}$ of the selected toxic metals in wastewater were determined before and after adsorption by Atomic Absorption Spectrophotometer (AA-6800, Shimadzu Japan).

\subsection{Batch adsorption study}

The adsorption capacities of purified CNTs (P-CNTs) and PEG functionalized CNTs (PEG-CNTs) for $\mathrm{Ni}, \mathrm{Fe}, \mathrm{Cu}, \mathrm{Pb}$ and $\mathrm{Cd}$ in wastewater samples were assessed via batch adsorption experiment at contact times of 10, 20, 30, 40, 50, 60 and $120 \mathrm{~min}$. P-CNTs and PEG-CNTs nanoadsorbent at $1.0 \mathrm{~g}$ each were measured in a $250 \mathrm{~cm}^{3}$ conical flask containing $50 \mathrm{~cm}^{3}$ of battery wastewater. The flask was corked, and the mixture was shaken at ambient temperature for $150 \mathrm{rpm}$ for respective time. Both tests were performed in duplicate, and the findings provided the average.

Upon achieving equilibrium, the solutions were filtered using $0.3 \mu \mathrm{m}$ membrane filter and the filtrate was analysed by AAS to determine the residual concentration of the toxic metals. The effect of nano-adsorbent dosage was examined by dispersing various amounts of nano-adsorbent dosage $(0.1,0.2,0.3,0.4 \mathrm{~g}$ to $0.5 \mathrm{~g})$ into $50 \mathrm{~cm}^{3}$ of battery wastewater in a $250 \mathrm{~cm}^{3}$ conical flasks of 250 $\mathrm{cm}^{3}$. The resultant mixture was corked and stirred for 90 minutes on a magnetic stirrer, then filtration followed. The filtrate was then analyzed using AAS to know the concentration of the selected heavy metals. The effect of temperature variability by the two materials on the efficiency of removal of selected heavy metals from the battery wastewater was investigated. The temperatures of the ultrasonic mixtures of $303,313,323,333$, and $343 \mathrm{~K}$ were filtered and the 
filtrates were analysed using AAS to examine the concentrations of the heavy metals after the equilibrium contact time.

The percentage removal $(\%)$ and adsorption capacity, $\mathrm{Q}(\mathrm{mg} / \mathrm{g})$ by nano-adsorbents were calculated using Eq. 2 and 3 respectively (Egbosiuba et al., 2021b; Jiang et al., 2016):

$$
\begin{aligned}
& \text { Removal rate }=\frac{\mathrm{C}_{0}-\mathrm{C}_{\mathrm{e}}}{\mathrm{C}_{0}} \times 100 \\
& \mathrm{Q}=\frac{\mathrm{V}\left(\mathrm{C}_{0}-\mathrm{C}_{\mathrm{e}}\right)}{\mathrm{W}} \times 100
\end{aligned}
$$

where $\mathrm{C}_{0}$ is defined as the initial concentration of the metal in the wastewater $(\mathrm{mg} / \mathrm{L}), \mathrm{C}_{\mathrm{e}}$ is the residual concentration of the metal ions $(\mathrm{mg} / \mathrm{L}), \mathrm{W}$ is the mass of the nanoadsorbent $(\mathrm{mg})$ and $\mathrm{V}$ is the volume of effluent $\left(\mathrm{dm}^{3}\right)$.

\section{Results and discussion}

\subsection{Parametric Studies on the CVD process}

Compared to several previous studies published by Kariim et al. (2016) and Ahmed et al. (2016), a relatively high yield of Carbon nanotubes was achieved in this study. This was due as a result of the great Fe-Ni catalytic activity and high kaolin support surface area. At reaction temperature of $750^{\circ} \mathrm{C}$, reaction time of 45 minutes, argon flow rate of $100 \mathrm{~mL} / \mathrm{min}$ and acetylene flow rate of 200 $\mathrm{mL} / \mathrm{min}$, an optimum yield of $321.6 \%$ was obtained. To demonstrate the reaction parameter dependence of CNTs, an analysis of variance (ANOVA) was performed to generate an empirical model for the main and combined effects of CVD process parameters on the CNTs yields. The multiple regression equation is as presented in equation (4):

$$
\begin{aligned}
& \text { Yield }=224.17-7.92 X_{1}-13.4 X_{2}+27.79 X_{3}+2.93 X_{4}+5.21 X_{1} X_{2}+0.29 X_{1} X_{3}+ \\
& 10.67 X_{1} X_{4}+10.40 X_{2} X_{3}-4.99 X_{2} X_{4}+18.9 X_{3} X_{4}-6.48 X_{1} X_{2} X_{3}-18.06 X_{1} X_{2} X_{4}- \\
& 22.41 X_{1} X_{3} X_{4}-18.43 X_{2} X_{3} X_{4}
\end{aligned}
$$


where $\mathrm{X}_{1}$ represents reaction temperature $\left({ }^{\circ} \mathrm{C}\right), \mathrm{X}_{2}$ represents the reaction time $(\mathrm{min}), \mathrm{X}_{3}$ represents argon flow rate $(\mathrm{mL} / \mathrm{min})$, and $\mathrm{X}_{4}$ represents acetylene flow rate $(\mathrm{mL} / \mathrm{min}) . \mathrm{It}$ was noticed from ANOVA that the reaction time $\left(\mathrm{X}_{2}\right)$, argon flow rate $\left(\mathrm{X}_{3}\right)$, the interactive $\mathrm{X}_{3} \mathrm{X}_{4}, \mathrm{X}_{1} \mathrm{X}_{2} \mathrm{X}_{4}, \mathrm{X}_{1} \mathrm{X}_{3} \mathrm{X}_{4}$, and $\mathrm{X}_{2} \mathrm{X}_{3} \mathrm{X}_{4}$ were the significant factors in the model at $(\mathrm{p}<0.05)$. A Model $F$-value of 283.50 was obtained, indicating the significant nature of the model.

\subsubsection{Influence of acetylene flow rate}

The CVD production rate of CNTs as a function of gas flow rate at various decomposition temperatures and constant argon flow rate is presented in Fig. 1.
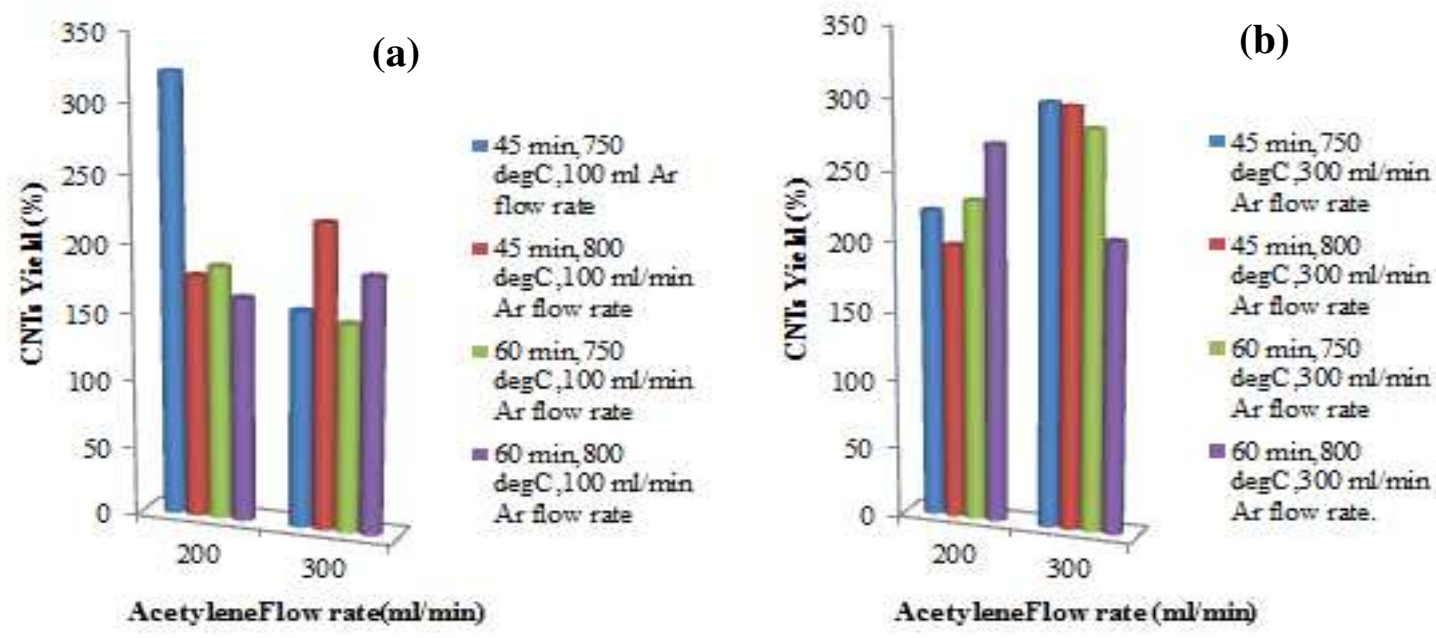

Figure 1: Effect of acetylene flow rate on CNTs yield at argon flow rates of (a) 100 $\mathrm{ml} / \mathrm{min}$, and (b) $300 \mathrm{ml} / \mathrm{min}$

The trend for the lower flow of argon carrier gas $(100 \mathrm{~mL} / \mathrm{min})$ as depicted in Fig. 1(a) shows that the yield of CNTs decreased as the flow rate of acetylene increased from $200 \mathrm{~mL} / \mathrm{min}$ to 300 $\mathrm{mL} / \mathrm{min}$. This may be related to the slow conversion of the Fe-Ni / kaolin catalyst to CNTs under low argon flow rate which acts as a carrier gas during the CVD reaction process to acetylene gas. This finding was also stated in the work of Aliyu et al. (2016), where slow incomplete reaction during acetylene pyrolysis was linked to low hydrogen. Nonetheless, in Fig. 1(b), as the flow rate of acetylene increased at a continuous argon flow rate of $300 \mathrm{~mL} / \mathrm{min}$ from $200-300 \mathrm{~mL} / \mathrm{min}$, the 
output rate of CNTs decreased, even at a reaction temperature of $800{ }^{\circ} \mathrm{C}$. In this case, the quantity of carbon left on the catalyst increased with a rise in the acetylene flow rate $(300 \mathrm{~mL} / \mathrm{min})$. The result corroborated Iyuke et al. (2010) study, which established that an increase in the production rate of CNTs at a higher acetylene flow rate and ascribed such an increase to the existence of a high-velocity profile responsible for the complete transformation of acetylene in the CVD reactor reaction region.

\subsubsection{Influence of argon flow rate}

The carrier gas (argon) flow rate was also observed to influence the production of CNTs in the CVD process, as shown in Fig. 2.
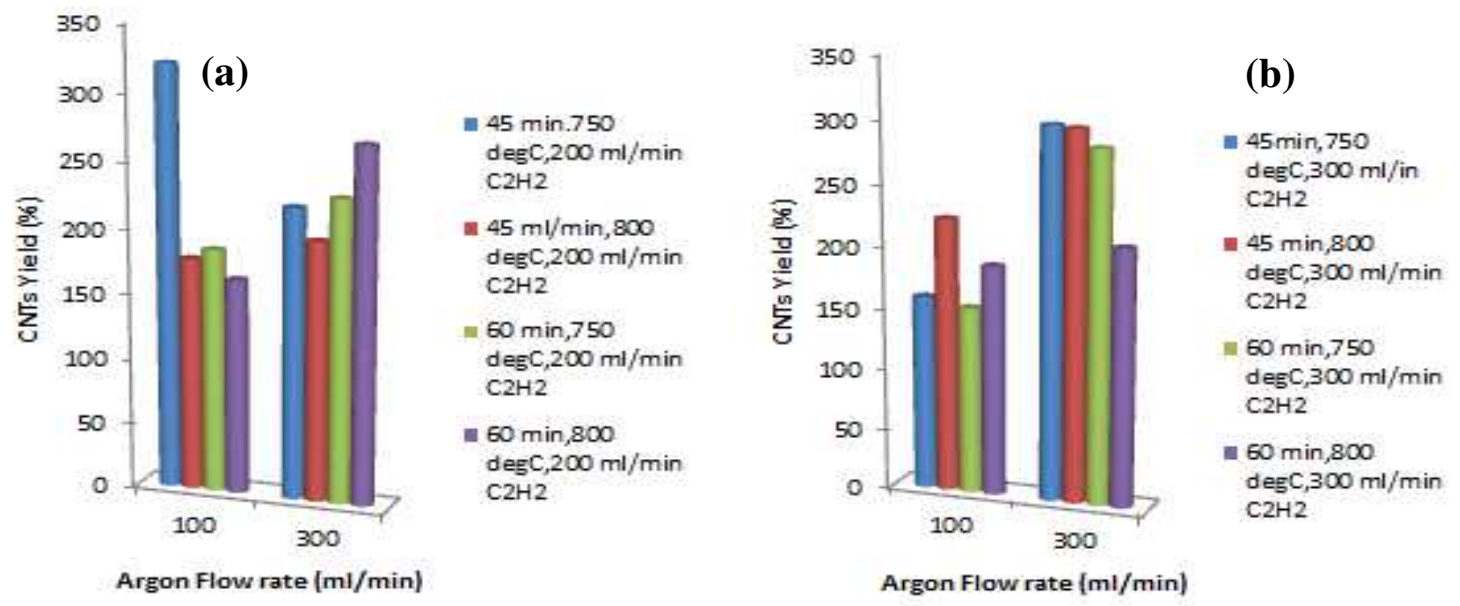

Figure 2: Effect of argon flow rate on CNTs yield at an acetylene flow rate of (a) 200 $\mathrm{ml} / \mathrm{min}$, and (b) $300 \mathrm{ml} / \mathrm{min}$

Fig. 2(a) shows that a rise in argon flow rate $(100 \mathrm{~mL} / \mathrm{min}-300 \mathrm{~mL} / \mathrm{min})$ at a constant acetylene flow rate of $200 \mathrm{~mL} / \mathrm{min}$ corresponds to an increase in the yield of CNTs except at $\left(750{ }^{\circ} \mathrm{C}, 45\right.$ min). Similarly, as the argon flow rate varied from $100 \mathrm{~mL} / \mathrm{min}$ to $300 \mathrm{~mL} / \mathrm{min}$ at a constant acetylene flow rate of $300 \mathrm{~mL} / \mathrm{min}$, the yield of CNTs also increased, Fig. 2(b) showed. This suggests that adding more argon could balance carbon diffusion and desorption on the surface of the kaolin-based bimetallic Fe-Ni catalyst responsible for carbon growth (Mohammed et al., 2016). 


\subsubsection{Influence of reaction temperature}

Also, based on previous literature reports on the temperature ranges suitable for CNTs production in CVD process (Nessim et al., 2010; Tessonnier and Sheng-Su, 2011; Cinar et al., 2012; Hanaei, 2013; Angulakshmi et al., 2015; Hassan, 2016), the reaction temperature in this study was varied between 750 and $800{ }^{\circ} \mathrm{C}$ to achieve desired CNTs formation and the outcome of reaction temperature on CNTs yield is described in Fig. 3.

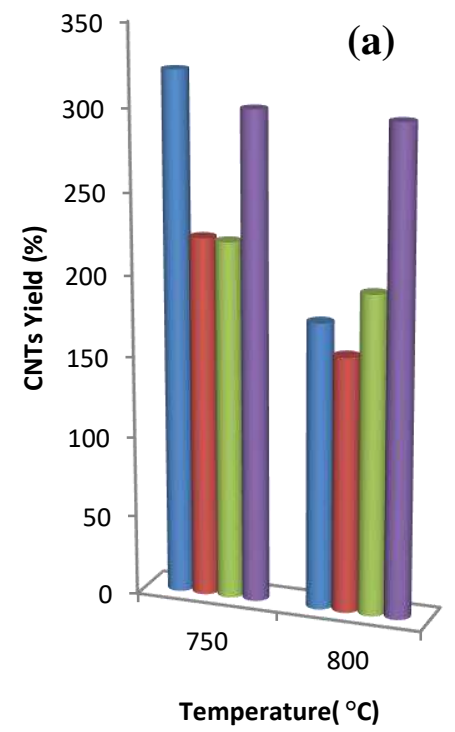

$45 \mathrm{~min}, 100 \mathrm{ml} / \mathrm{min}$ $\mathrm{Ar}, 200 \mathrm{ml} / \mathrm{min} \mathrm{C} 2 \mathrm{H} 2$

$45 \mathrm{~min}, 100 \mathrm{ml} / \mathrm{min}$ $\mathrm{Ar}, 300 \mathrm{ml} / \mathrm{min} \mathrm{C} 2 \mathrm{H} 2$ $45 \mathrm{~min}, 300 \mathrm{ml} / \mathrm{min}$ $\mathrm{Ar}, 200 \mathrm{ml} / \mathrm{min} \mathrm{C} 2 \mathrm{H} 2$ - $45 \mathrm{~min}, 300 \mathrm{ml} / \mathrm{min}$ $\mathrm{Ar}, 300 \mathrm{ml} / \mathrm{min} \mathrm{C} 2 \mathrm{H} 2$

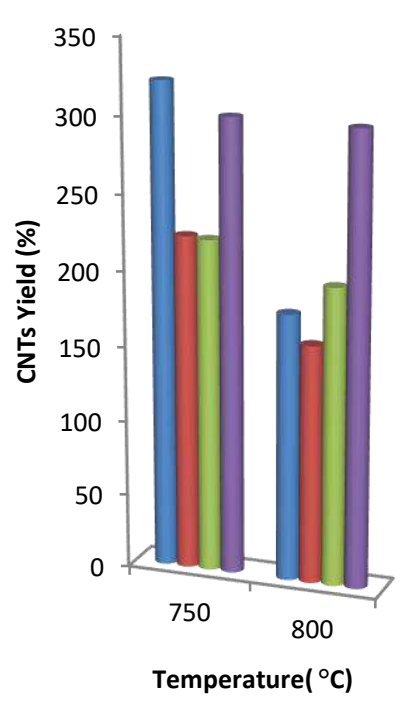

(b)

— $45 \mathrm{~min}, 100 \mathrm{ml} / \mathrm{min}$ $\mathrm{Ar}, 200 \mathrm{ml} / \mathrm{min}$ $\mathrm{C} 2 \mathrm{H} 2$

- $45 \mathrm{~min}, 100 \mathrm{ml} / \mathrm{min}$ $\mathrm{Ar}, 300 \mathrm{ml} / \mathrm{min}$ $\mathrm{C} 2 \mathrm{H} 2$

$45 \mathrm{~min}, 300 \mathrm{ml} / \mathrm{min}$ Ar, $200 \mathrm{ml} / \mathrm{min}$ $\mathrm{C} 2 \mathrm{H} 2$

$45 \mathrm{~min}, 300 \mathrm{ml} / \mathrm{min}$ $\mathrm{Ar}, 300 \mathrm{ml} / \mathrm{min}$ $\mathrm{C} 2 \mathrm{H} 2$

Figure 3: Effect of temperature on CNTs yield at (a) 45 min growth time (b) 60 min growth time

Fig. 3(a) shows a decline in the yield of CNTs at a constant growth time of 45 min. Fig. 3(b) also shows a decrease in the yield of CNTs as the temperature rose from 750 to $800{ }^{\circ} \mathrm{C}$ at a constant growth time of $60 \mathrm{~min}$. This result indicated that CNT synthesis was favoured at $750{ }^{\circ} \mathrm{C}$ compared to $800{ }^{\circ} \mathrm{C}$.

\subsubsection{Effect of reaction time}

Studies had shown that the reaction time could influence the quality and yield of CNTs produced via a CVD process (Hsieh et al., 2009; Chiwaye, 2012; Kariim et al., 2016, Abdulkareem et al., 
2017; Hanaei, 2013). In the present study, the growth time was varied from 45 to 60 min and the effect on the yield is shown in Fig. 4.
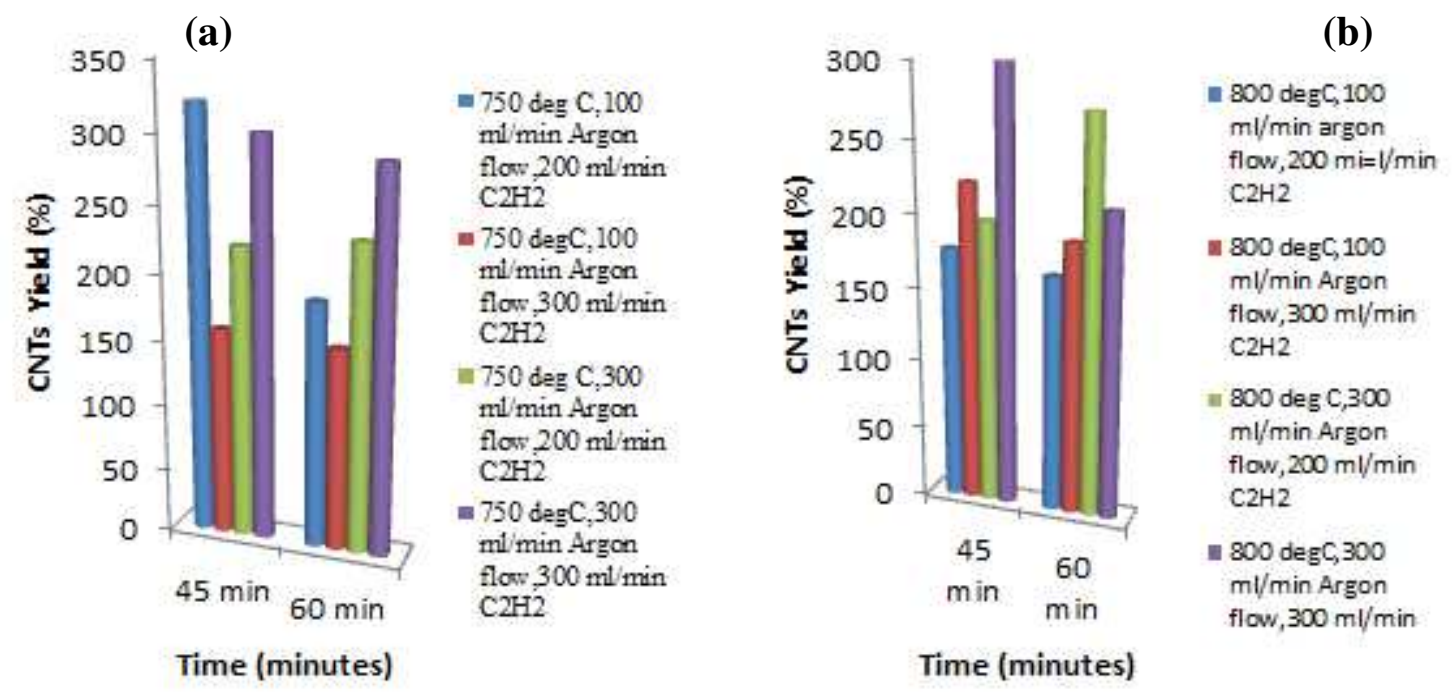

Figure 4: Effect of time on CNT yield at the temperature of (a) $700^{\circ} \mathrm{C}$, and $(b) 7^{\circ} 0^{\circ} \mathrm{C}$

From Fig. 4(a) and (b) it can be observed that growth time plays a significant role with respect to CNT yield. As the growth time increased from 45 to 60 min (as seen in Fig. 4a), the yield of CNTs was correspondingly decreased. Similar patterns were found once again in Fig. 4 (b). It may be due to longer-term catalyst deactivation (Abdulkareem et al., 2017). Many works of literature have identified a deposition period of $45 \mathrm{~min}$ as the optimum time to produce a high yield of CNTs and, beyond this time of production, the yield has been found to decrease due to deactivation and decrease of the active catalyst site (Hanaei, 2013; Abdulkareem et al., 2017).

\subsection{Properties of the synthesized CNTs}

\subsubsection{BET surface area of CNTs}

The specific surface area of as-synthesized CNTs obtained at the optimum reaction condition, its purified (P-CNTs) and PEG-functionalized form (PEG-CNTs) were analysed and the obtained results were shown in Table 2 . 
Table 2: BET surface area of as-synthesized, purified CNTs and PEG-CNTs

\begin{tabular}{lccc}
\hline & As-synthesized CNTs & Purified CNTs & PEG-CNTs \\
\hline BET surface area $\left(\mathrm{m}^{2} / \mathrm{g}\right)$ & 583.31 & 781.88 & 970.81 \\
Pore volume $\left(\mathrm{cm}^{3} / \mathrm{g}\right)$ & 0.2963 & 0.325 & 0.346 \\
Pore size $(\mathrm{nm})$ & 2.983 & 3.098 & 3.251 \\
\hline
\end{tabular}

Table 2 shows that the adopted purification method has a great influence on the surface area, pore volume and pore size of CNTs due to the opening of both CNT end caps and sidewalls (Sonia et al., 2011). The improvement in specific surface area, pore volume and pore size might also be due to removing impurities from large unreacted metallic particle sizes. Moreover, when PEG was impregnated with the tube-like structure of CNTs, an enhancement in surface area, pore depth, and pore volume was obtained as more functional groups were added.

\subsubsection{XRD analysis of raw CNTs, P-CNTs and PEG-CNTs}

The crystalline nature and the phase types of the two materials were investigated using XRD and result are presented in Fig. 5. 


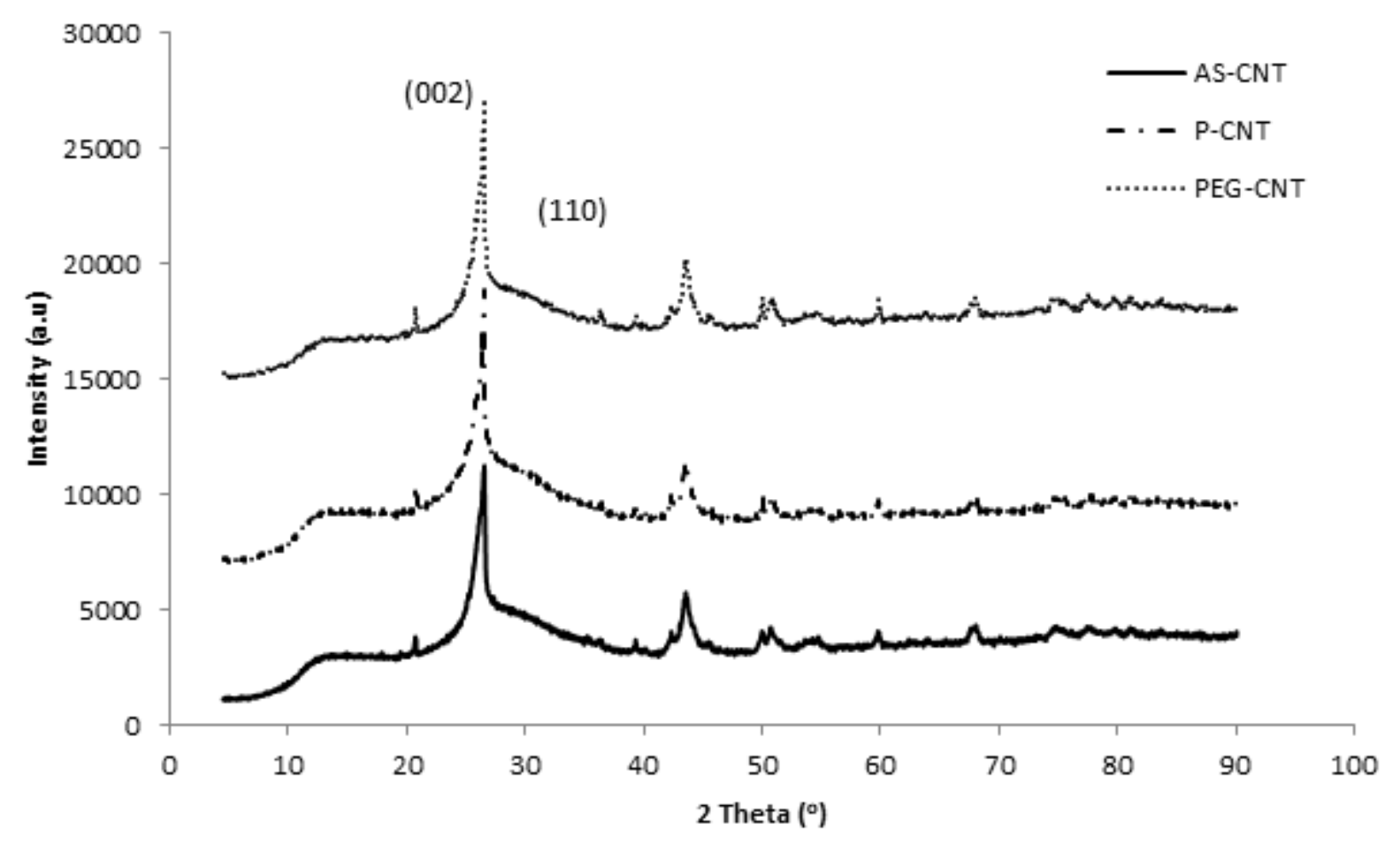

Figure 5: XRD patterns for as-synthesized, purified, and PEG-functionalized CNTs

The XRD patterns of as-synthesized, purified-CNTs and PEG-CNTs, as shown in Fig. 5, showed two prominent peaks at $2 \theta$ of $26.32^{\circ}$ and $43.35^{\circ}$ with corresponding miller indices of (002) and (110) attributed to carbon peaks. The diffraction peak with miller index (002) corresponds respectively to hexagonal graphite or also referred to as the inter-layered spacing between neighbouring graphite layers. The (002) reflection peak was observed for as-synthesized, P-CNTs and PEG-CNTs at the same 2 theta values, indicating that the structure of the CNTs was not distorted despite purification and functionalization with PEG; rather, the peak intensity increases, a proof of the crystallinity of the mineral phase. The miller indices of (002) and (110) of CNTs correspond respectively to the spacing of $0.3456 \mathrm{~nm}$ and $03213 \mathrm{~nm}$ with determined crystallite sizes of $1.96 \mathrm{~nm}$ and $2.77 \mathrm{~nm}$. 


\subsubsection{FTIR analysis of the raw CNTs, P-CNTs and PEG-CNTs}

Fourier Transform Infrared (FTIR) analysis was carried out to identify the functional groups present or introduced in the-synthesized CNTs, P-CNTs and PEG-CNTs and the FTIR spectra are presented in Figure 6.

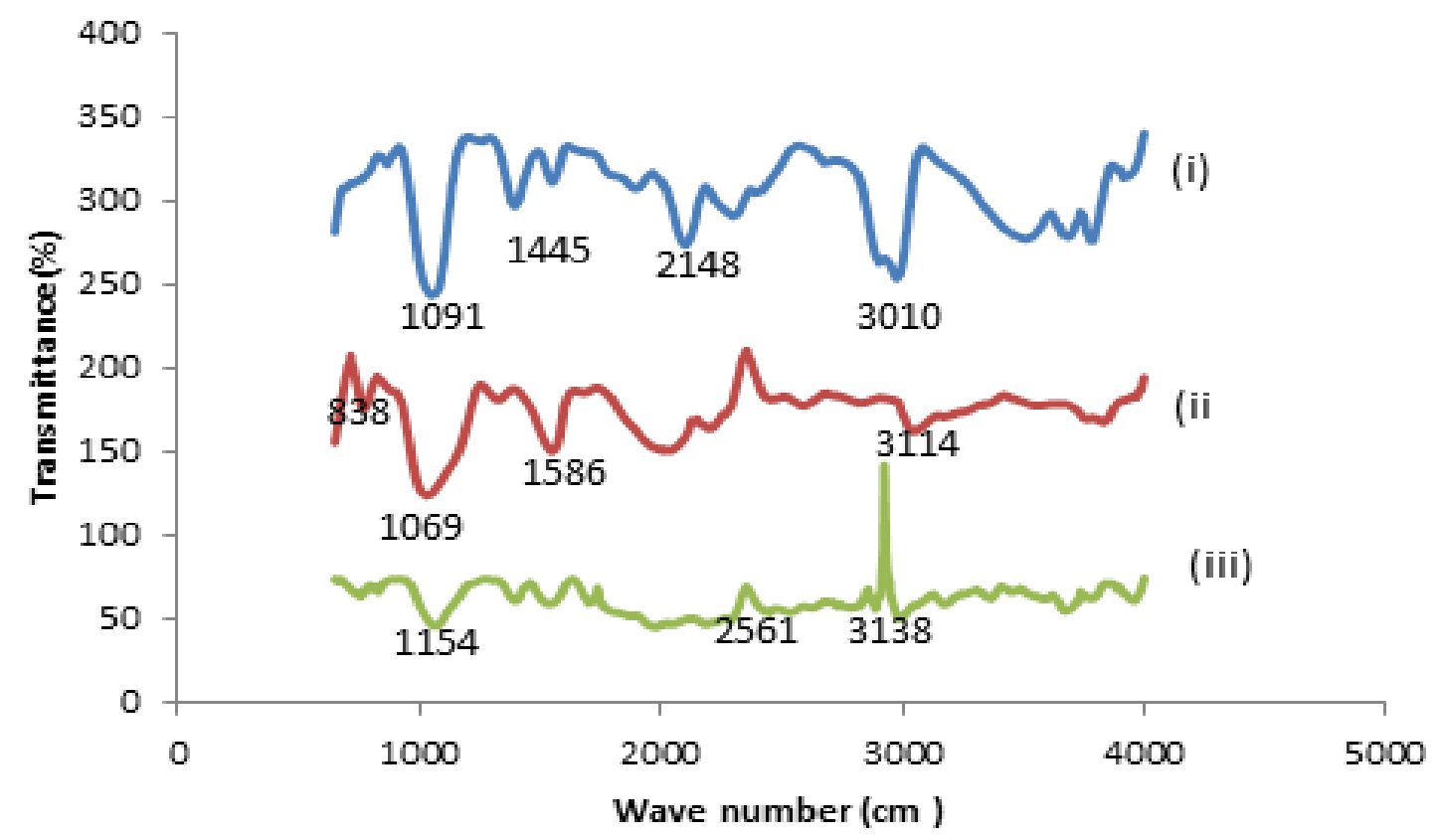

Figure 6: FTIR spectra of (i) As-synthesized CNTs, (ii) Purified CNTs, and (iii) PEG functionalized CNTs

In the as-synthesized CNTs, the absorption peak of $1091 \mathrm{~cm}^{-1}$ agrees with the presence of $-\mathrm{OH}$ (hydroxyl group), assigned to C-C stretching at $1445 \mathrm{~cm}^{-1}$, a slightly different value from that obtained at $1500 \mathrm{~cm}^{-1}$ by Yesil and Bayran (2011). The change can be due to the nature of the material in support and the carbon precursor used in carbon nanotubes processing. The absorption peak at $2148 \mathrm{~cm}^{-1}$ relates to the bond $\mathrm{C}=\mathrm{C}$ (Kausar, 2016) and shows the presence of $-\mathrm{OH}$ at 3010 $\mathrm{cm}^{-1}$.

The absorption spectrum for the P-CNTs shows peaks at $1586 \mathrm{~cm}^{-1}$ and $3114 \mathrm{~cm}^{-1}$ reflecting the hydroxyl group ( $-\mathrm{OH})$ and the carboxylic functional group $(-\mathrm{COOH})$ respectively, which were introduced into the P-CNT surface during the purification process (Shirazi et al., 2011). The 838 
$\mathrm{cm}^{-1}$ absorption peak corresponds to the deformation of the plane and the vibrations of the alkyl groups present on the CNT surface. After P-CNTs were modified with PEG, the $-\mathrm{C}=\mathrm{O}$ functional ester group was observed at $1154 \mathrm{~cm}^{-1}$. The peak observed at $2561 \mathrm{~cm}^{-1}$ corresponds to PEG alkyl group C-H stretching vibrations (Mohammed and Robert, 2013).

\subsubsection{The Morphological Analysis}

The HRSEM images of the three samples (as-synthesized CNTs, the P-CNTs, and PEG-CNTs) as shown in Fig. 7 provided the morphologies and network structures.

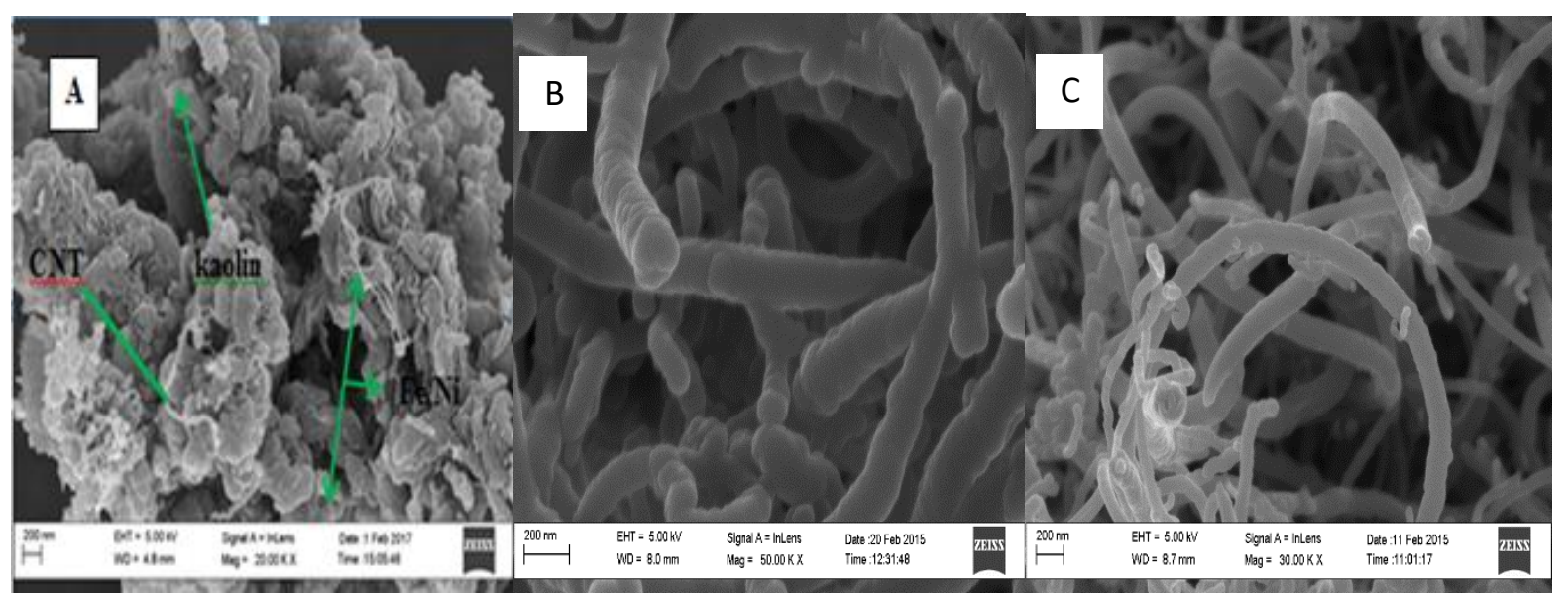

\section{Figure 7: HRSEM patterns of (a) as-synthesized CNTs (b) P-CNTs, and (c) PEG-CNTs}

Fig. 7(a) shows that as-synthesized CNTs was in nature rough, spongy, and agglomerated, in the form of clusters of carbonaceous material on the CNT surface. The synthesized CNTs were also non-uniform, fibrous and irregular, attributable to self-pyrolysis of CNTs at a temperature of 750 ${ }^{\circ} \mathrm{C}$. In Fig. 7(b), the CNTs array was aligned, erect, forming long, thin and thick tubes of different diameters due to the reduction and removal of amorphous carbon through the purification process. A vertically oriented, long and thick-like narrow tube of uniform diameter was observed in PEGCNTs shown in Fig. 7(c), which was caused by the added polymer matrix that helped to disperse CNTs. After functionalization, the diameter of the CNTs obtained increased significantly due to the addition of more functional group such as $-\mathrm{COOH},-\mathrm{OH}$ and $\mathrm{H}-\mathrm{C}-\mathrm{H}$ on the surface of CNTs. 


\subsubsection{The Microstructural analysis}

Further investigation on the morphologies and microstructures of the as-synthesized CNTs, the PCNTs, and PEG-CNTs was conducted by HRTEM and their corresponding micrograph is shown in Fig. 8.

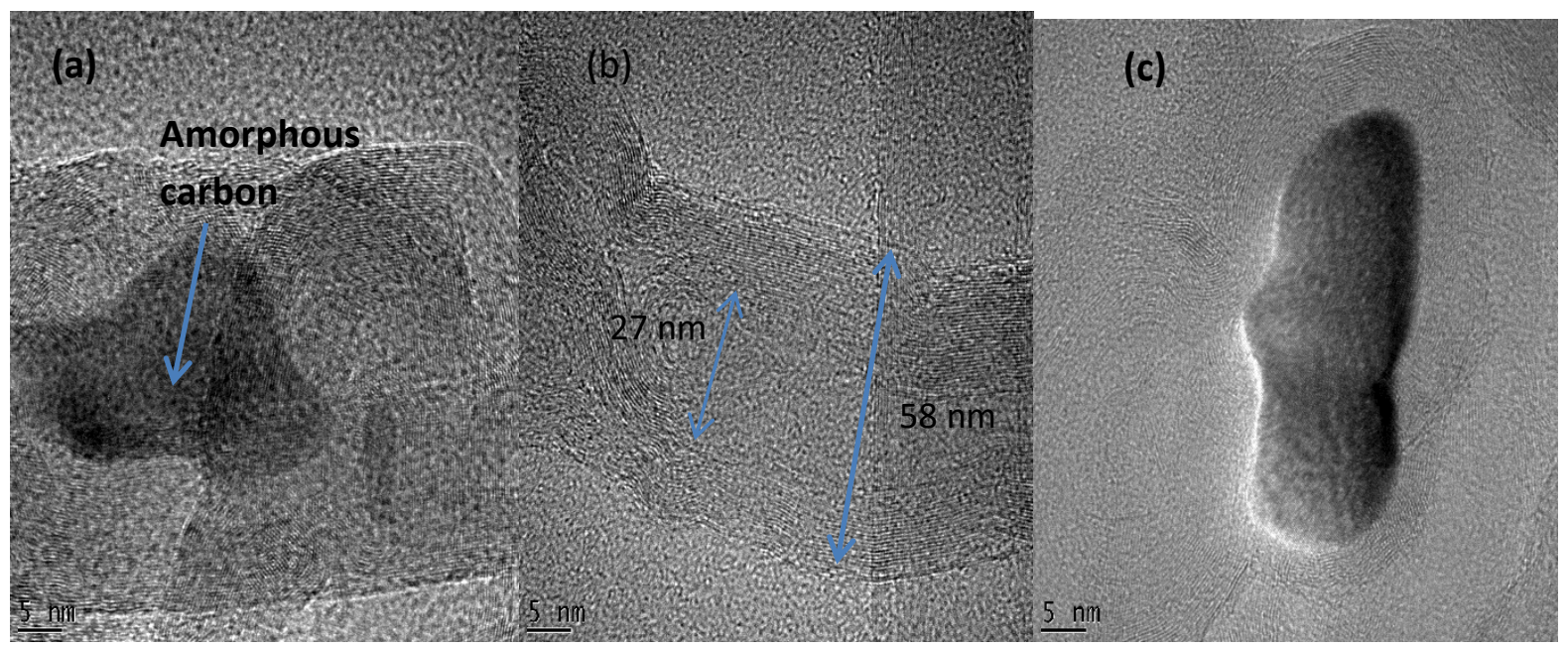

Figure 8: HRTEM patterns of (a) as-synthesized CNTs, (b) purified CNTs, (c) PEG-CNTs

The HRTEM image of as-synthesized CNTs in Fig. 8(a) suggested the presence of a dense black coloured spot that could be due to amorphous carbon and residual particles from supporting kaolin catalysts. However, after acid treatment, the carbonaceous material and other impurities present on the surface of as-synthesized CNTs were significantly reduced as shown in Fig. 8(b). The internal and external diameters of purified CNTs were $27 \mathrm{~nm}$ and $58 \mathrm{~nm}$, respectively. After the CNTs functionalized with PEG, a protruding dark spot was observed within the CNTs' tubular network.

\subsubsection{Elemental compositions analysis of the prepared nanomaterials}

The EDS of the A-CNTs, P-CNTs, and PEG-CNTs showing the compositions of elements are depicted in Fig. 9 (a), (b) and (c). 


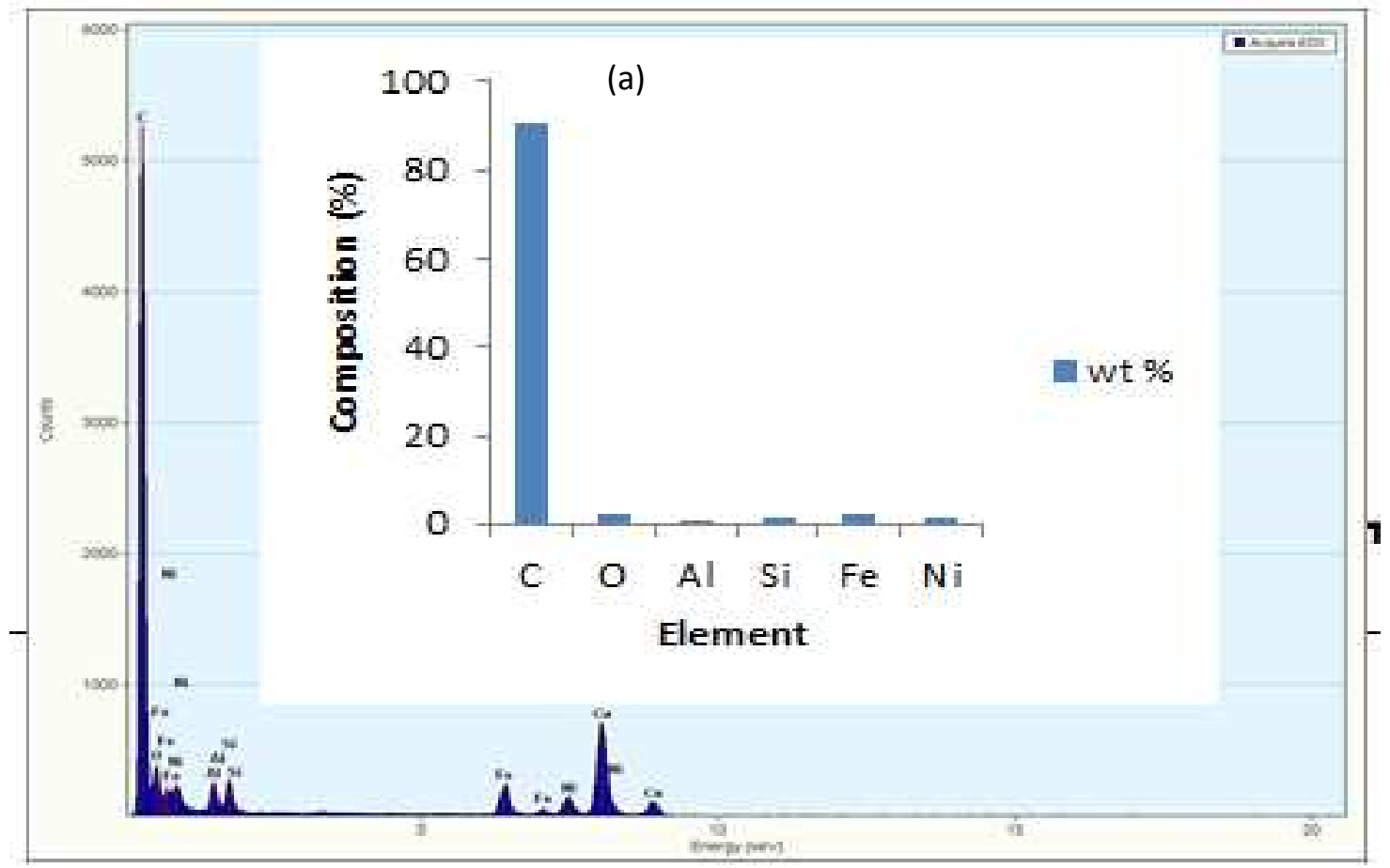

Figure 9 (a): TEM and EDS analysis of as-synthesized CNTs

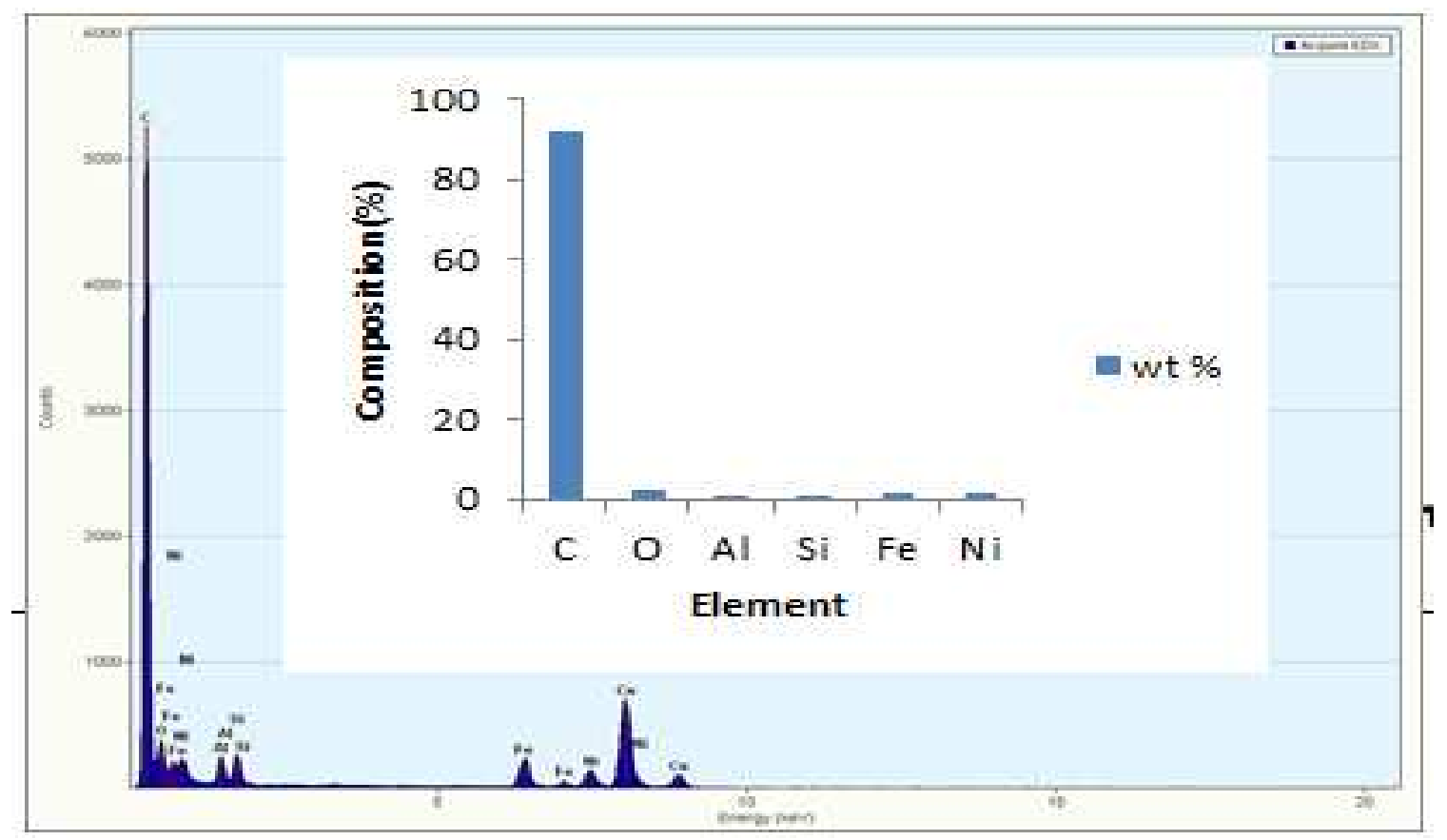

Figure 9 (b): TEM and EDS analysis of purified CNTs 


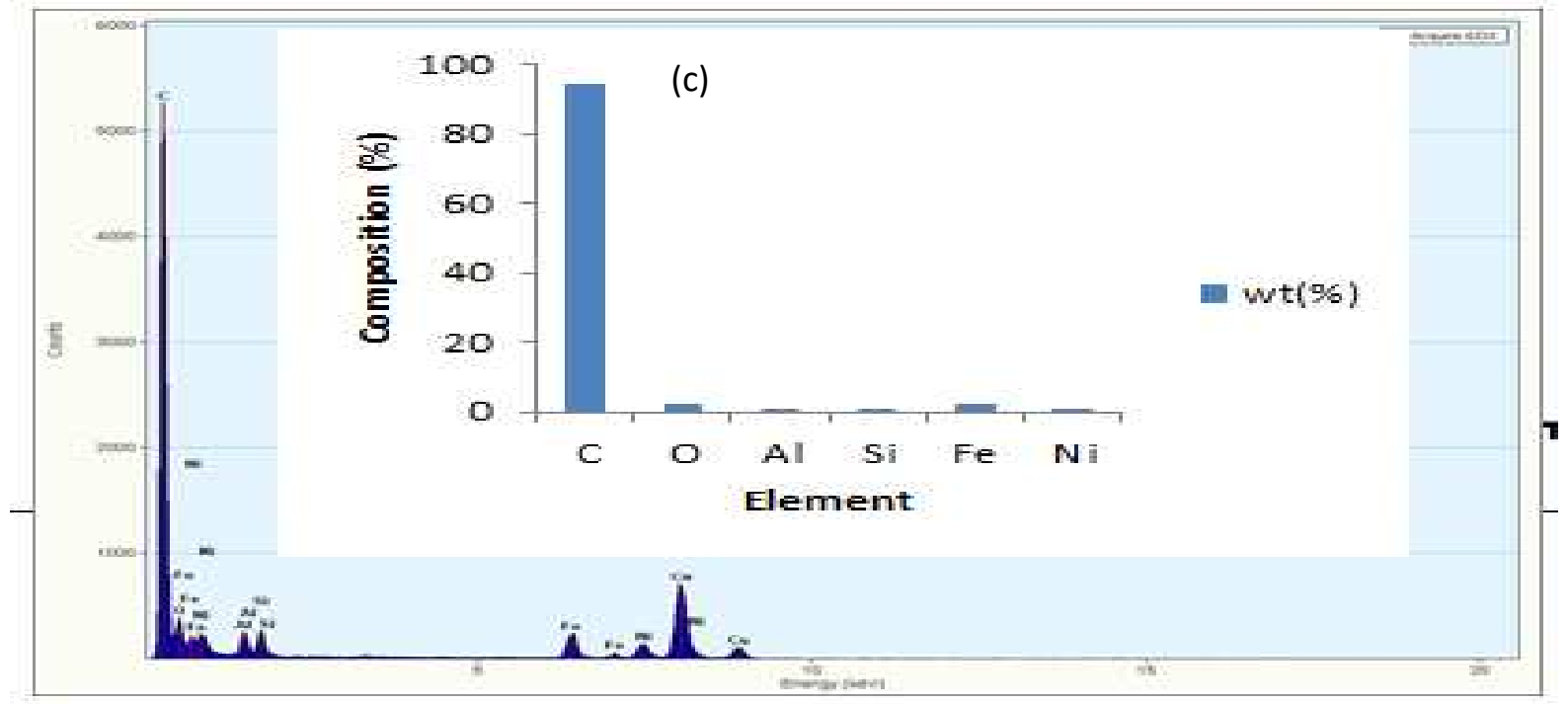

Figure 9(c): TEM and EDS analysis of PEG-functionalized CNTs

Fig. 9 (a), (b) and (c) provided the percentage elemental composition of C, O, Al, Si. Fe and Ni in different proportions. In all the spectra of the synthesized CNTs, the amount of carbon established was higher than other elements present which confirm the presence of the graphene sheet of CNTs. The elements $\mathrm{Al}, \mathrm{Si}, \mathrm{O}, \mathrm{Fe}$ and $\mathrm{Ni}$ in as-synthesized CNTs instigated from kaolin as support and $\mathrm{Fe} / \mathrm{Ni}$ as a metal catalyst, respectively (as shown in Fig. 9 a). While in Fig. 9 (b) and (c), the percentage composition of the impurities in as-synthesized CNTs reduced after purification and functionalization. This suggests that purification and functionalization have helped in the removal of impurities which may affect the efficiency of CNTs during application for wastewater treatment. Again, the oxygen peak in the spectra (Fig. 9 a, b and c) increased after functionalization which can be attributed to the incorporation of functional group by PEG. The carbon content in assynthesized CNTs was found to increase from 81.23 to $94.18 \%$ after functionalization.

\subsubsection{The Diameter distribution}

CNTs are applied based on a diameter size distribution that defines their physical properties such as metallicity, thermal properties and curvature radius that affect surface function (Chen et al., 2014). Fig 10 (a) and (b) demonstrated the distribution of P-CNTs and PEG-CNTs in diameters 
and the distribution of particle sizes may influence the nano-adsorbent suspensibility and adsorption properties (Heithmar and Pergantis, 2010).

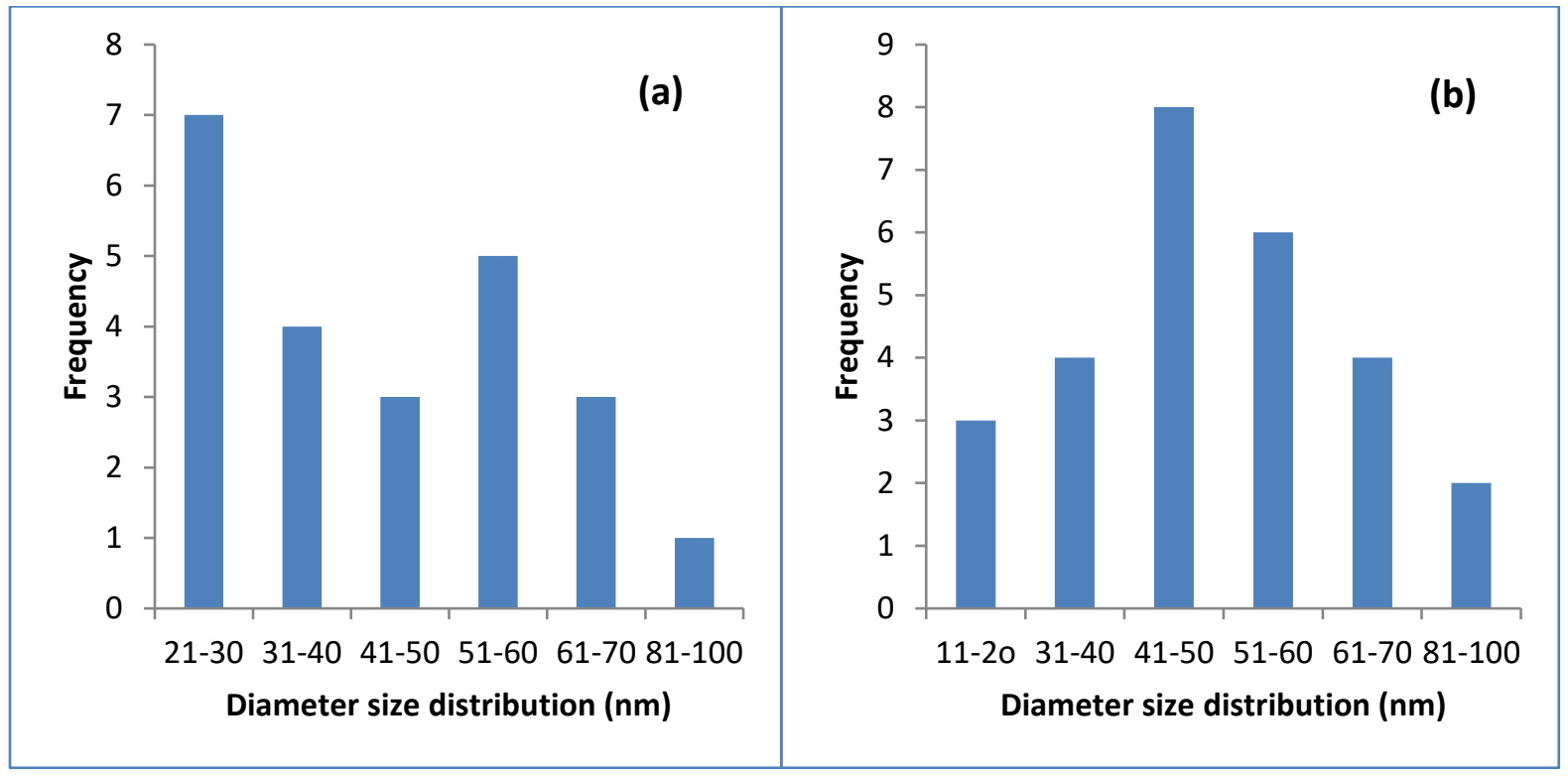

Figure 10: Diameter size distribution of (a) purified CNTs, and (b) PEG-CNTs

The result obtained shows that the size distribution for P-CNTs ranges from $21 \mathrm{~nm}$ to $100 \mathrm{~nm}$ (Fig. 10(a)), whereas for the PEG-CNTs, Fig. 10(b) indicated a size distribution range from $11 \mathrm{~nm}$ to $100 \mathrm{~nm}$. This difference in the distribution of diameters can be attributed to modifying P-CNTs with PEG, which increases the number of functional groups on CNTs.

\subsection{Physicochemical properties of battery wastewater}

Table 3 presents the physicochemical properties of raw and treated wastewater from the battery industry. Results show that raw battery wastewater has a $\mathrm{pH}$ of 1.2 , which is highly acidic and therefore lower than the prescribed ranges of 6.5-8.5 (WHO, 2011; NESERA, 2011). The lower $\mathrm{pH}$ may be due to the presence of lead $(\mathrm{Pb})$ used in battery manufacturing and low and the low $\mathrm{pH}$ range may be linked to the high level of acidic constituents such as sulphide and cyanide in the wastewater (Lokhande et al., 2012). 
The $\mathrm{pH}$ increased significantly to the range of 6.30-6.45 depending on the nano-adsorbents used after the treatment with the nano-adsorbents, thereby falling within the acceptable range. The fall in $\mathrm{pH}$ may be related by the nano-adsorbents in the wastewater to the sorption of acidic matters. The battery effluent conductivity value was $16,400 \mu \mathrm{S} / \mathrm{cm}$ which was high though. It means that the wastewater contains significant quantities of ionic charged species, indicating hazard and pollution danger to marine life without treatment. The minimum allowable Electrical Conductivity limit is $1000 \mu \mathrm{S} / \mathrm{cm}$ (WHO, 2011). However, when the battery effluent was treated with nanoadsorbents, conductivity values, chloride ions, and other anions like fluoride, sulphate, nitrite, and nitrate were substantially reduced which were lower than the permissible limits of WHO (2011) and National Environmental Standards Regulatory and Enforcement Agency (NESREA, 2011). The industrial effluent has $10,986 \mathrm{mg} / \mathrm{L}$ of total dissolved solids, indicating a high value and being unacceptable for discharging such wastewater into surface water bodies; it has a health hazard and may cause gastrointestinal problems (Lokhande et al., 2012). The value reduced significantly to the guidelines of WHO (2011) and NESREA (2011), after treatment with nanoadsorbents. The battery industrial effluent DO is $3.11 \mathrm{mg} / \mathrm{L}$ lower than the World Health Organization's 5-6 mg/L set (WHO, 2011). The National Environmental Standards Regulatory and Enforcement Agency (NESREA) has set a minimum discharge limit of $4 \mathrm{mg} / \mathrm{L}$. After adsorption, the battery wastewater DO was increased, and the values obtained were fairly within the requirements, thus promoting the living organism.

Battery wastewater has a BOD value of $22.0 \mathrm{mg} / \mathrm{L}$ which means that the effluent has high biodegradable content for its decomposition and less oxygen. And with low dissolved oxygen, wastewater with high BOD has the same effect. They both caused aquatic organisms to suffocate 
and die. Nonetheless, satisfactory results were obtained when nano-adsorbents were used to treat the industrial effluent and the values are within recommended standards.

As regards COD, raw wastewater values of $680 \mathrm{mg} / \mathrm{L}$ were obtained, suggesting that it has high organic matter which is not within the appropriate guidelines (WHO, 2011; NESREA, 2011). The two requirements were met after the adsorption experiments. After treatment of raw wastewater, the phosphate content was also increased to the standards. Before the-treatment with nanoadsorbents, the untreated battery wastewater reveals the presence of organic matter, anions, and heavy metals demonstrating low quality. Table 3 shows the overall evaluation indicated that nanoadsorbents have been efficient and effective in handling wastewater from the batteries. 
Table 3: Physicochemical properties of the raw battery industrial wastewater and after adsorption process using nano-adsorbents

\begin{tabular}{|c|c|c|c|c|c|c|c|}
\hline \multirow[b]{2}{*}{ Parameter } & \multirow[b]{2}{*}{ Raw } & \multicolumn{2}{|c|}{$\begin{array}{c}\text { Effect of Temp. } \\
\left({ }^{\circ} \mathrm{C}\right)\end{array}$} & \multicolumn{2}{|c|}{ Effect of dosage $(\mathrm{g})$} & \multirow{2}{*}{$\begin{array}{c}\text { NESREA } \\
\text { (2011) } \\
\text { Limit }\end{array}$} & \multirow{2}{*}{$\begin{array}{l}\text { WHO } \\
(2011) \\
\text { Limit }\end{array}$} \\
\hline & & $\begin{array}{c}\text { P- } \\
\text { CNTs }\end{array}$ & $\begin{array}{l}\text { PEG- } \\
\text { CNTs }\end{array}$ & $\begin{array}{c}\text { P- } \\
\text { CNTs }\end{array}$ & $\begin{array}{l}\text { PEG- } \\
\text { CNTs }\end{array}$ & & \\
\hline $\mathrm{pH}$ & 1.2 & 6.30 & 6.45 & 6.35 & 6.40 & $6.5-8.5$ & $5.5-8.5$ \\
\hline TDS (mg/ L) & 10,986 & 267 & 230 & 254 & 211 & -- & 600 \\
\hline Conductivity $(\mu \mathrm{S} / \mathrm{cm})$ & 16,400 & 399 & 344 & 379 & 315 & -- & 1000 \\
\hline Dissolved Oxygen (mg/L) & 3.11 & 5.12 & 5.55 & 5.75 & 5.85 & 4.0 & $5-6$ \\
\hline Nitrate (mg/L) & 328 & 3.89 & 3.57 & 3.60 & 2.60 & 40 & 50 \\
\hline Ammonium (mg/L) & 5.00 & 0.00 & 0.00 & 0.00 & 0.00 & 2.0 & $1.5 / 0.5$ \\
\hline Chloride (mg/L) & 2730 & 32.2 & 52.9 & 55.2 & 32.2 & 350 & 250 \\
\hline Phosphate (mg/L) & 1.70 & 0.05 & 0.01 & 0.04 & 0.00 & 3.5 & 0.5 \\
\hline Cyanide (mg/L) & 0.50 & 0.00 & 0.00 & 0.00 & 0.00 & 0.10 & 0.05 \\
\hline Fluoride $(\mathrm{mg} / \mathrm{L})$ & 5.40 & 0.13 & 0.11 & 0.12 & 0.09 & ---- & $1.5 / 1$ \\
\hline Sulphate (mg/L) & 112 & 0.00 & 0.00 & 0.00 & 0.00 & 500 & $250 / 200$ \\
\hline $\mathrm{COD}(\mathrm{mg} / \mathrm{L})$ & 680 & 13.0 & 10.0 & 4.75 & 2.30 & 30 & 40.0 \\
\hline BOD5 (mg/L) & 22.0 & 3.05 & 2.50 & 1.15 & 1.12 & 6.0 & $10 / 5-7$ \\
\hline Nitrite (mg/L) & 0.24 & 0.04 & 0.04 & 0.03 & 0.04 & 0.8 & $3 / 0.5$ \\
\hline Total Bacteria Count (cfu/ml) & 0 & 0 & 0 & 0 & 0 & ---- & --- \\
\hline Copper (mg/L) & 1.3909 & & & & & 0.01 & 0.1 \\
\hline Iron $(\mathrm{mg} / \mathrm{L})$ & 19.533 & & & & & 0.3 & 0.3 \\
\hline Lead (mg/L) & 2.3508 & & & & & 0.01 & 0.01 \\
\hline Cadmium (mg/L) & 0.0408 & & & & & 0.01 & 0.01 \\
\hline Nickel (mg/L) & 0.7008 & & & & & 0.25 & 0.25 \\
\hline
\end{tabular}




\subsection{Parametric Studies in batch adsorption}

\subsubsection{Effect of contact time}

The effects of contact time on the batch adsorption process are shown in Fig. 11(a) and 11(b) for P-CNTs and PEG-CNTs respectively.

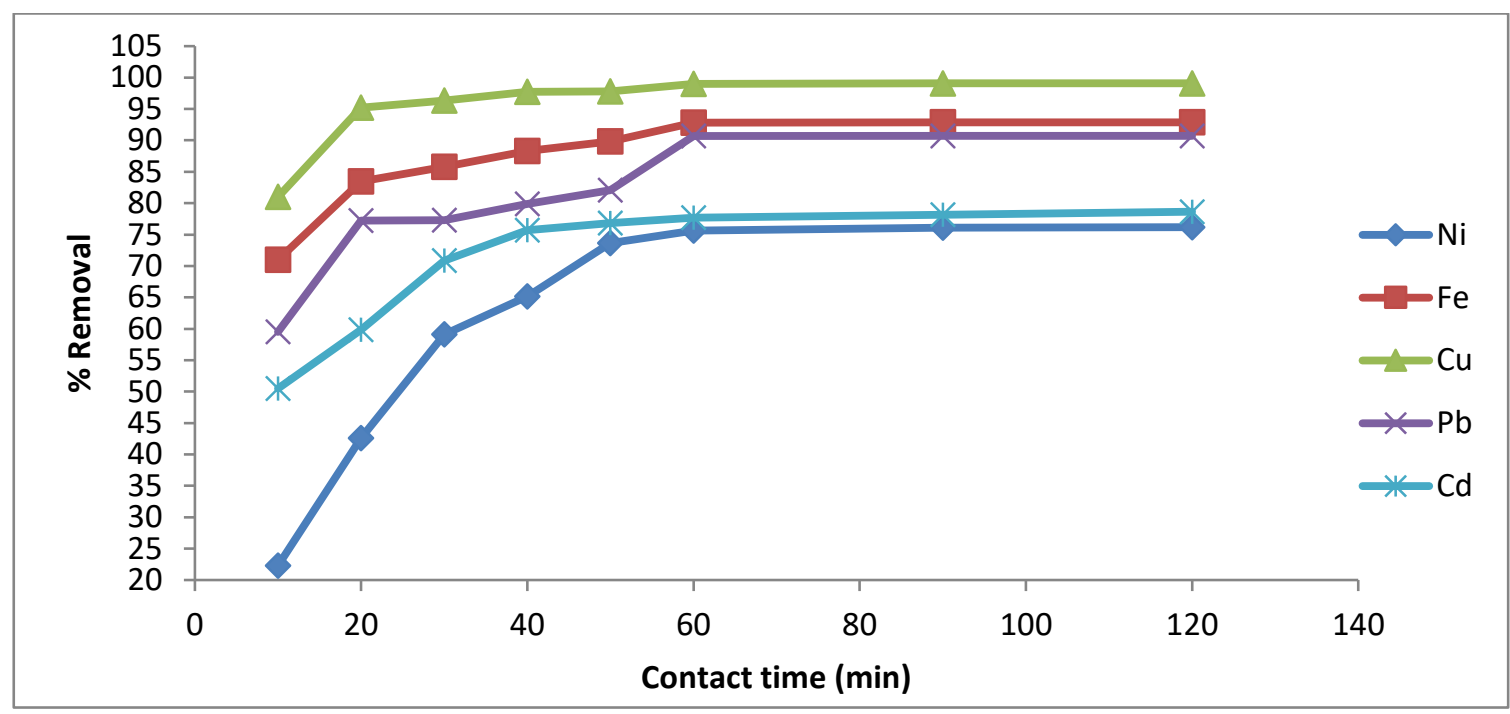

Figure 11: Effect of contact time using P-CNT at nano-adsorbent dosage (0.1 g), temperature $\left(25^{\circ} \mathrm{C}\right)$, agitation speed $(150 \mathrm{rpm})$ and volume of battery wastewater $(50$

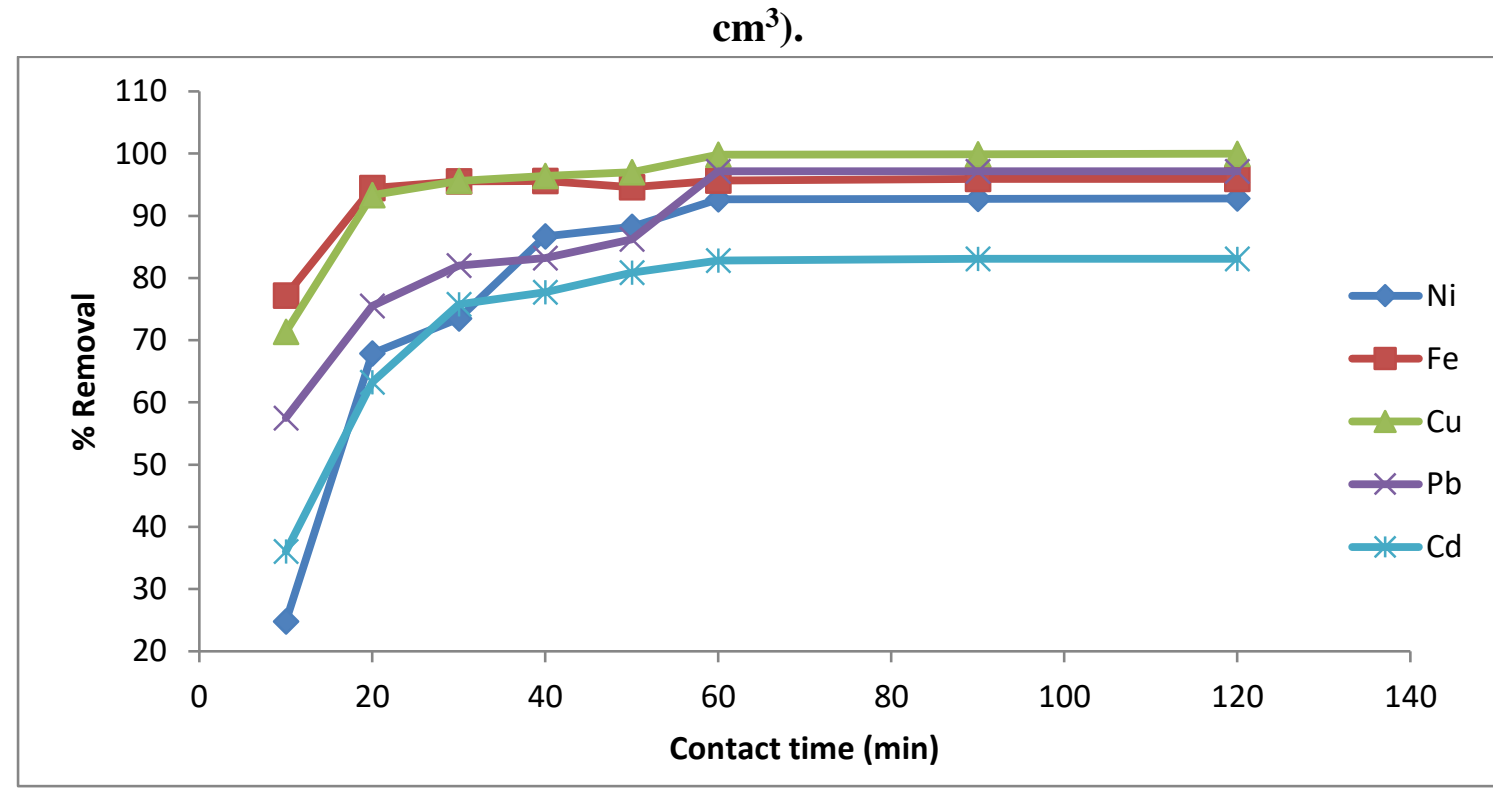

Figure 11 (b): Effect of contact time on using PEG-CNT at adsorbent dosage (0.1 g), temperature $\left(25^{\circ} \mathrm{C}\right)$, agitation speed $(150 \mathrm{rpm})$ and volume of wastewater $\left(50 \mathrm{~cm}^{3}\right)$

Fig. 11(a) and (b) showed that the removal efficiency of P-CNTs and PEG-CNTs for the targeted heavy metals increases gradually with the contact time and remains stable for up to 90 
$\min$. The increased removal efficiency as a function of the reaction time regardless of the nanoadsorbents could be linked to the availability of active binding sites and the formation of strong electrostatic attraction between the sorbents and the sorbate. There has also been intense competition among the metals on the surface of the nano-adsorbents for the small binding sites. At 90 minutes the equilibrium time was reached and the percentage of metal ions removed by P-CNTs was $\mathrm{Cu}$ (99.09), $\mathrm{Pb}$ (90.72), $\mathrm{Ni}$ (76.12), $\mathrm{Fe}$ (92.87), and $\mathrm{Cd}$ (78.64). The pattern of the percentage metal ion removed can be expressed in the order $\mathrm{Cu}>\mathrm{Fe}>\mathrm{Pb}>\mathrm{Cd}>\mathrm{Ni}$. This can be attributed to the smaller ionic radius $(0.69 \AA)$ of $\mathrm{Cu}$ moved faster to P-CNT pores than $\mathrm{Ni}$ with a greater ionic radius $(0.84 \AA)$. Similarly, at equilibrium time of $90 \mathrm{~min}$, the percentages of adsorbed metal ions on PEG-CNTs were 92.79, 95.93, 99.99, 83.41 and 97.16 for Ni, Fe, $\mathrm{Cu}, \mathrm{Cd}$ and $\mathrm{Pb}$, respectively. In general, it was observed that the PEG- CNTs effectively removed heavy metal ions more than P-CNTs at each reaction time under the same conditions applied. The discrepancies may be as a result of the large surface area, more functional groups and negative charges on the PEG-CNT surface than the P-CNTs (Chen et al., 2008; Zhang et al., 2015). The findings indicate that the removal of heavy metals using these nanomaterials was highly dependent upon the reaction time.

\subsubsection{Effect of nano-adsorbents dosage}

The effect of adsorbents dosage varying from 0.1 to $0.5 \mathrm{~g} / 50 \mathrm{~cm}^{3}$ on the percentage removal of the targeted heavy metals from battery wastewater are presented in Fig. 12 (a) and (b). 


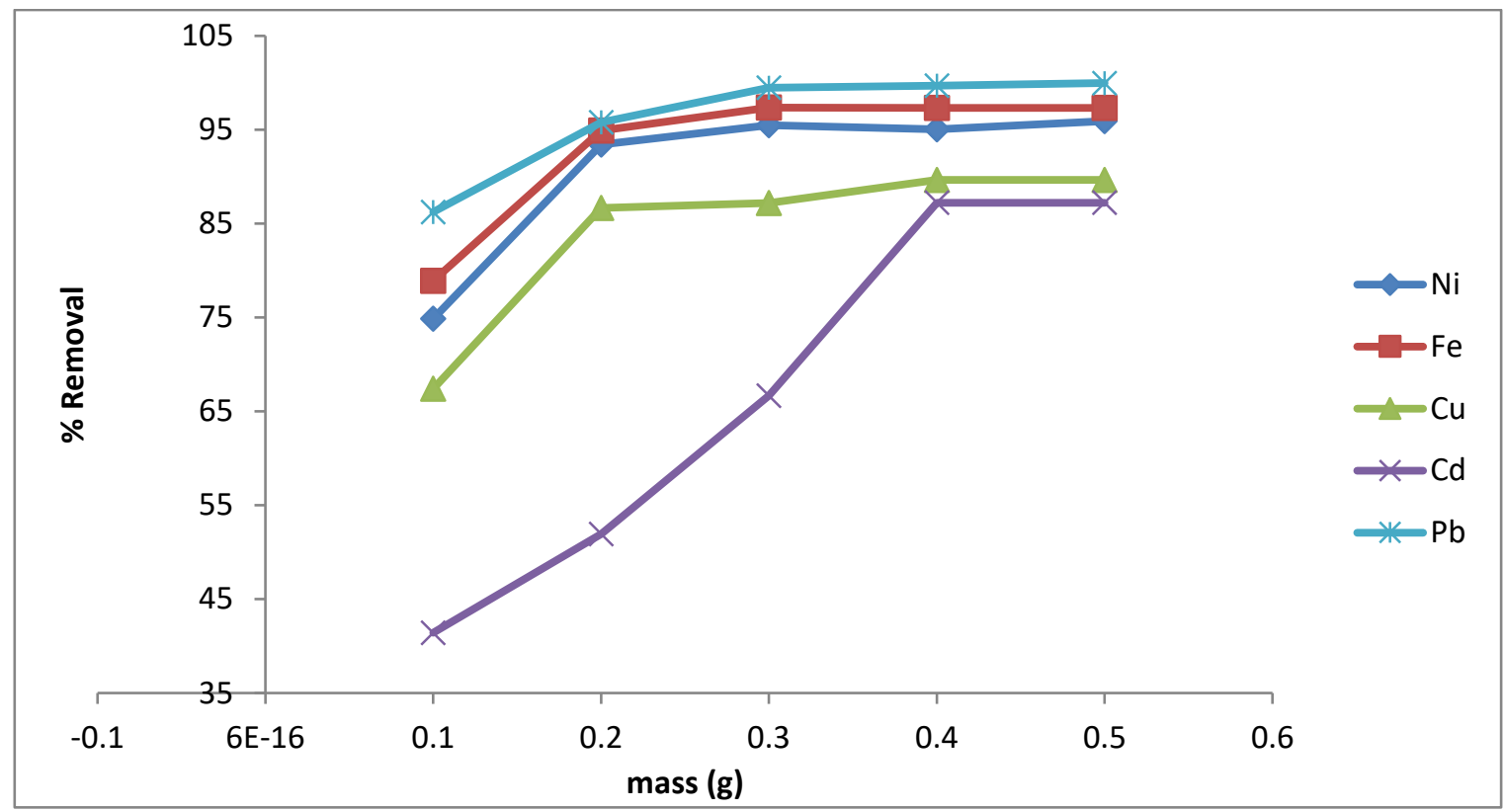

Figure 12 (a): Effect of nano-adsorbent dosage on metal ions using P-CNTs at respect contact times, agitation speed $(150 \mathrm{rpm})$, temperature $\left(25^{\circ} \mathrm{C}\right)$ and volume of wastewater $\left(50 \mathrm{~cm}^{3}\right)$

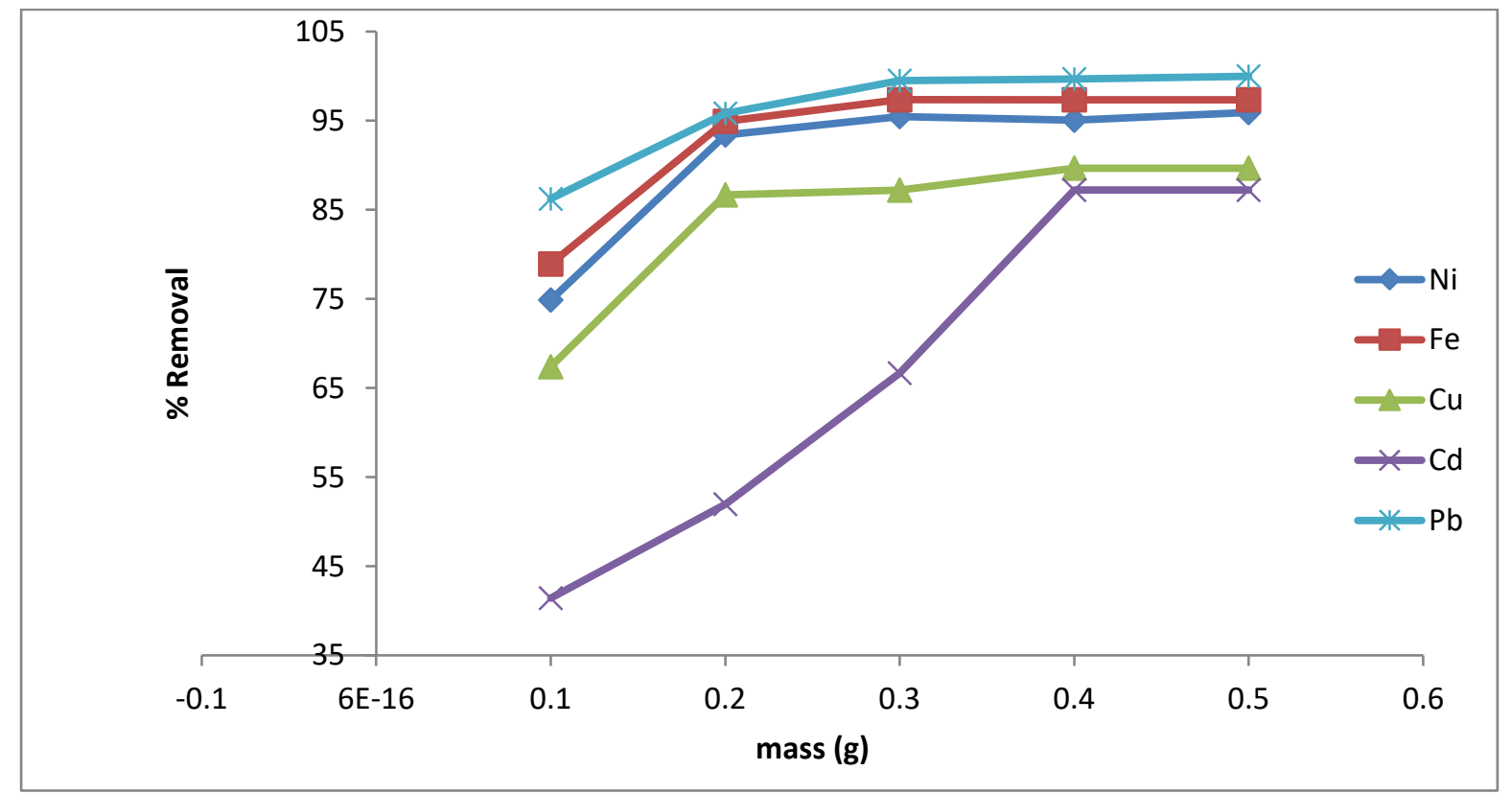

Figure 12(b): Effect of nano-adsorbent dosage on metal ions using PEG-CNTs at respective contact times, agitation speed $(150 \mathrm{rpm})$, temperature $\left(25^{\circ} \mathrm{C}\right)$ and volume of wastewater $\left(50 \mathrm{~cm}^{3}\right)$

The experimental results showed that metal ion removal efficiencies slowly increased as the nano-adsorbent dosage being used increase. This may be attributable to the fact that increased dosage of nano-adsorbents stimulates a larger surface area or more adsorption sites for the 
targeted heavy metal ions. The optimal dosage for P-CNTs and PEG-CNTs was, as shown in Figure $12(\mathrm{a})$ and (b), $0.4 \mathrm{~g}$ and $0.3 \mathrm{~g}$ respectively. Owing to the addition of more active sites the maximum removal efficiency was obtained from PEG-CNTs. Furthermore, the higher removal efficiency of PEG-CNTs may also be linked to the presence of more oxygenous functional groups that reacted with the metals and formed salt or possibly complex deposits on the PEG-CNT surface. Further increase in the amount of nano-adsorbents (0.1-0.5 g) did not significantly alter the percentage of metal ions. Also, a very slow increase in removal efficiency after equilibrium attainment may be attributed to over-saturation of binding sites as well as electrostatic repulsion between the positively charged metal ions and the negatively charged carbon nanotubes.

\subsubsection{Effect of temperature}

The influence of temperature on the adsorption of heavy metals by nano-adsorbents was studied at various temperatures of $30,40,50,60$ and $70^{\circ} \mathrm{C}$, and the results are given in Fig. 13(a) and (b).

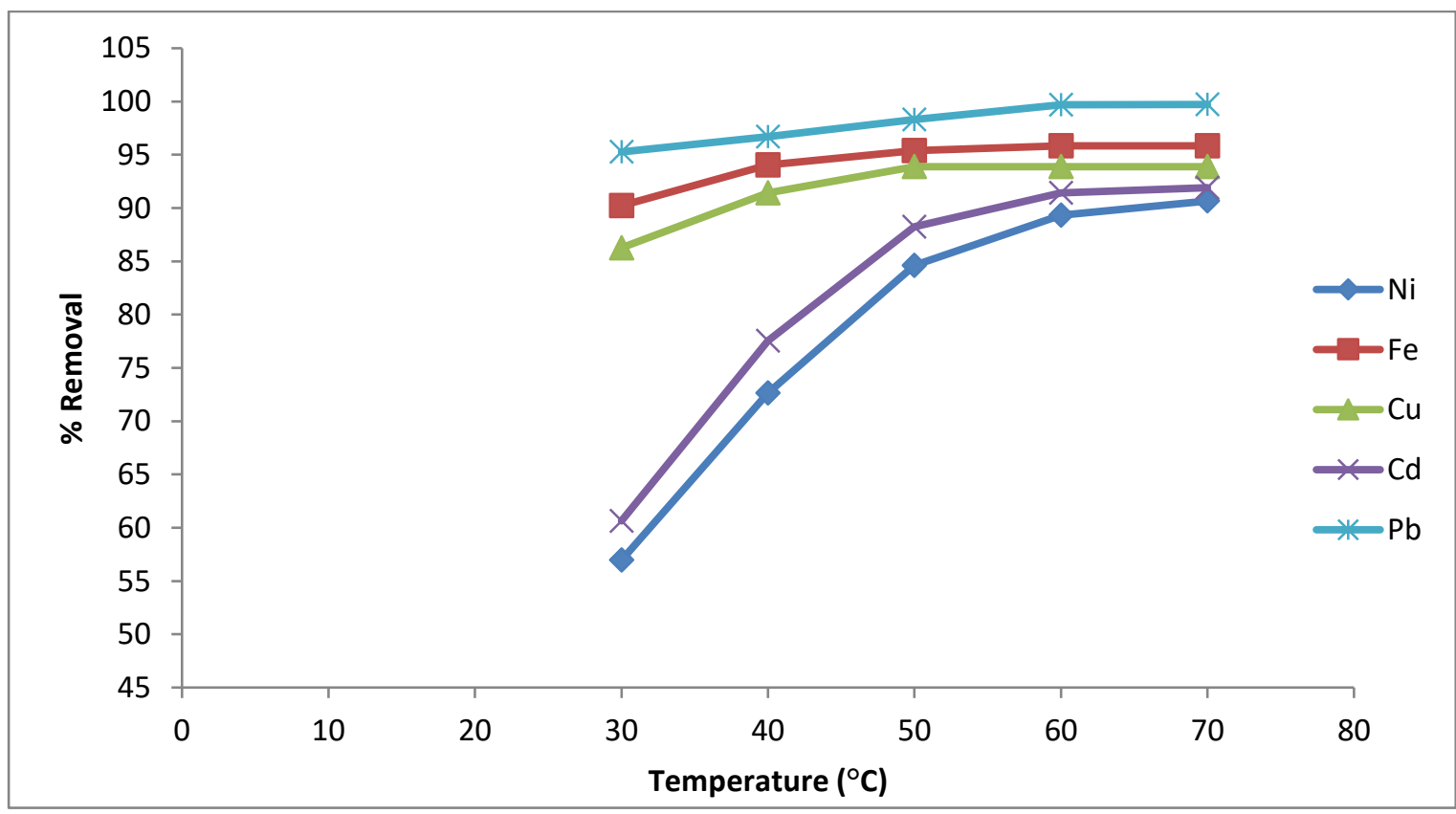

Figure 13(a): Effect of temperature on metal ions using P-CNTs at respect contact times, adsorbent dosage $(0.4 \mathrm{~g})$, stirring speed $(150 \mathrm{rpm})$ and volume of wastewater (50 $\left.\mathbf{c m}^{3}\right)$ 


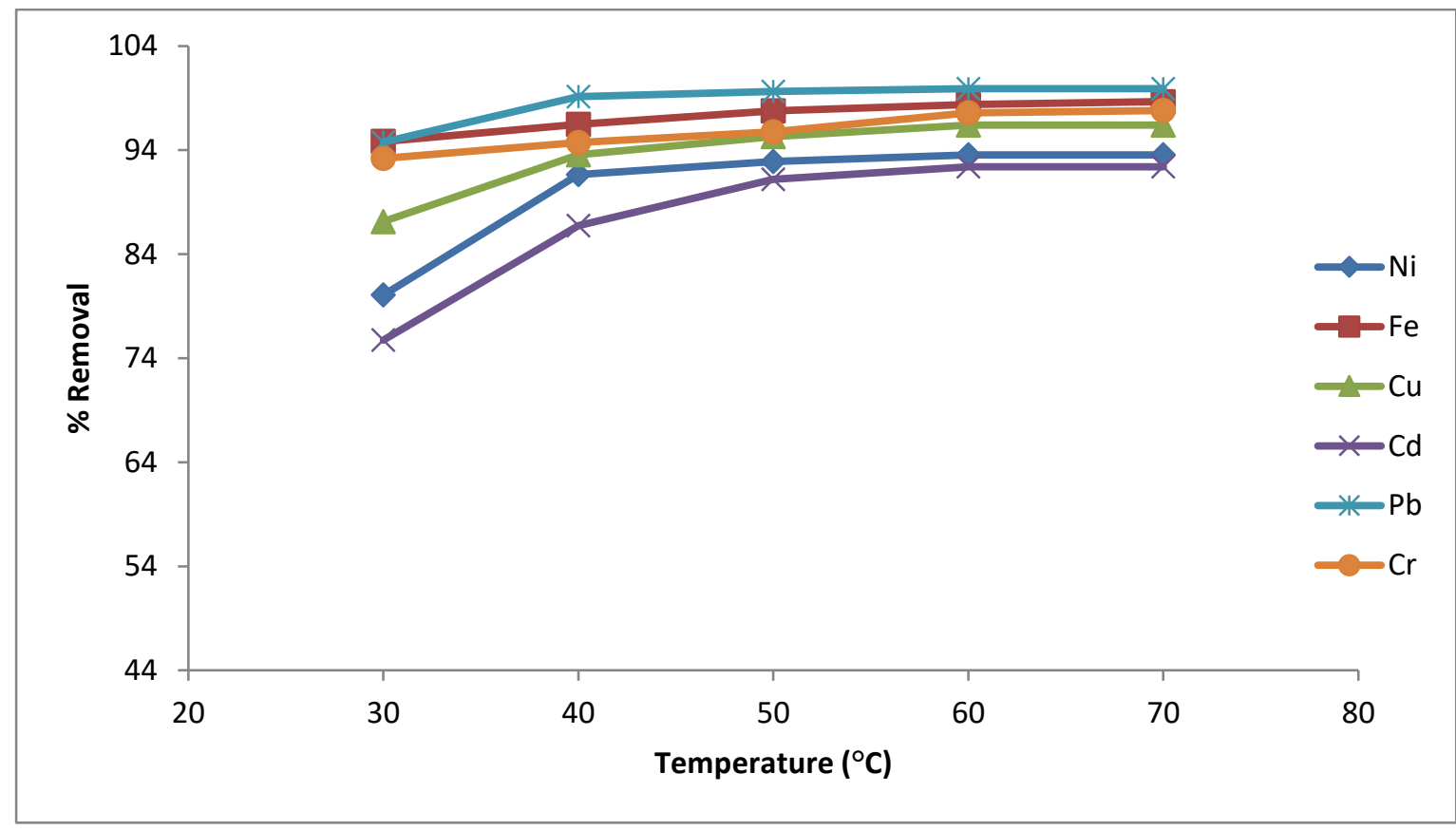

Figure 13(b): Effect of temperature on metal ions using PEG-CNTs at respect contact times, adsorbent dosage $(0.4 \mathrm{~g})$, stirring time $(150 \mathrm{rpm})$ and volume of wastewater $(50$ $\left.\mathbf{c m}^{3}\right)$

An improvement in the removal efficiency of the heavy metals with temperature increase was observed on both nano-adsorbents, according to Fig. 13 (a) and (b). These findings suggest an endothermic process of the adsorption mechanism that occurred as a result of increased metal mobility thus increasing the contact rate in the nano-adsorbent active sites.

Nevertheless, various types of behaviours, such as increase/decrease in adsorption study, have been known to have the outcome of temperature in most adsorption processes (Dawoduet al., 2012). The optimum temperature at equilibrium for P-CNTs and PEG-CNTs was $60 \mathrm{oC}$ and $50 \mathrm{oC}$ respectively. After the achievement of equilibrium, further, rise in temperature had a negligible effect on the efficiency of metal removal. Due to the large surface area and functional groups on its surface, the PEG- CNTs exhibited improved adsorption efficiency than the PCNTs. 


\subsection{Adsorption isotherm}

Equilibrium adsorption isotherms of the batch adsorption process were investigated using Langmuir and Freundlich isotherm models. The Langmuir model which is fitted for monolayer adsorption on the surface (Luo et al., 2013) is shown in Equ. (5):

$$
\frac{\mathrm{C}_{\mathrm{e}}}{\mathrm{q}_{\mathrm{e}}}=\frac{1}{\mathrm{q}_{\mathrm{m}} \mathrm{K}_{\mathrm{L}}}+\frac{\mathrm{C}_{\mathrm{e}}}{\mathrm{q}_{\mathrm{m}}}
$$

where $C_{e}$ is the equilibrium concentration of the metal $(\mathrm{mg} / \mathrm{L}), \mathrm{q}_{\mathrm{e}}$ is the quantity of adsorbate at equilibrium $(\mathrm{mg} / \mathrm{g}), \mathrm{q}_{\mathrm{m}}$ is the maximum adsorption capacity $(\mathrm{mg} / \mathrm{g})$ and $\mathrm{K}_{\mathrm{L}}$ is the Langmuir

constant associated with affinity binding site. A plot of $\frac{\mathrm{C}_{\mathrm{e}}}{\mathrm{q}_{\mathrm{e}}}$ against $\mathrm{C}_{\mathrm{e}}$ gave a straight line and the slope, intercept and maximum adsorption capacity of adsorbate were calculated as presented in Table 1. The Freundlich equation is an empirical model based on multilayer adsorption of sorbent and the isotherm model as shown in Equ. (6):

$$
\log \mathrm{q}_{\mathrm{e}}=\log \mathrm{K}_{\mathrm{f}}+\frac{1}{n} \log \mathrm{C}_{\mathrm{e}}
$$

where $\mathrm{q}_{\mathrm{e}}$ is the amount of adsorbate on adsorbent at equilibrium $(\mathrm{mg} / \mathrm{g})$, $\mathrm{K}_{\mathrm{f}}$ is a constant relating to the adsorption capacity $(\mathrm{mg} / \mathrm{g})$ and $\frac{1}{n}$ is an empirical factor relating to the adsorption intensity. A plot of $\log q_{\mathrm{e}}$ against $\log \mathrm{C}_{\mathrm{e}}$ would result in a straight for the determinations of slope $\left(\frac{1}{n}\right)$ and intercept $\mathrm{k}_{\mathrm{f}}$ respectively (Bankole et al., 2017). The parameters and correlation coefficients of the adsorption isotherms of P-CNTs are shown in Table 4. 
Table 4: Isotherm model parameters for adsorption of metal ions onto P-CNTs

\begin{tabular}{llllll}
\hline $\begin{array}{l}\text { Isotherm } \\
\text { Parameters }\end{array}$ & $\mathrm{Ni}$ & $\mathrm{Fe}$ & $\mathrm{Cu}$ & $\mathrm{Cd}$ & $\mathrm{Pb}$ \\
\hline Langmuir & & & & & \\
$\mathrm{q}_{\mathrm{e}}(\mathrm{mg} / \mathrm{g})$ & 145.96 & 166.67 & 183.25 & 172.75 & 154.47 \\
$\mathrm{R}^{2}$ & 0.9459 & 0.8971 & 0.8499 & 0.6113 & 0.5744 \\
$\mathrm{R}_{\mathrm{L}}$ & 0.2296 & 0.5559 & 1.2368 & 0.0891 & 0.1002 \\
Freundlich & & & & & \\
$\mathrm{K}_{\mathrm{f}}$ & 0.3673 & 2.7246 & 1.1612 & 0.0202 & 1.059 \\
$\mathrm{n}$ & 1.6260 & 1.2750 & 0.6052 & 3.3025 & 4.5620 \\
$\mathrm{R}^{2}$ & 0.8980 & 0.8295 & 0.8615 & 0.7468 & 0.9040 \\
\hline
\end{tabular}

Table 4 shows that all the separation factor $\mathrm{R}_{\mathrm{L}}$ for selected heavy metals $(\mathrm{Ni}, \mathrm{Fe}, \mathrm{Pb}, \mathrm{Cd}, \mathrm{Cr}$ and $\mathrm{Zn}$ ) was within a range of 0 -1, which confirms a favourable uptake for targeted heavy metal ions except $\mathrm{Cu}$ where $\mathrm{R}_{\mathrm{L}}$ is greater than one $\left(\mathrm{R}_{\mathrm{L}}>1\right)$. The adsorption of Ni favours Langmuir isotherm because the values of the correlation coefficient $\left(R^{2}\right)$ is close to unity $(>0.9)$, while $\mathrm{Cu}, \mathrm{Pb}, \mathrm{Cd}$, and $\mathrm{Fe}$ are not in favour of Langmuir Isotherm. The good agreement with the Langmuir model of equilibrium sorption data is an indication that Ni's adsorption on P-CNTs is of a monolayer type. Sahika and Ozgen (2014) stated that $\mathrm{n}$ value higher than one indicated a physical process of favour. The result shown in Table 4 indicates that for all selected metal except $\mathrm{Cu}(\mathrm{n}<1)$, P- CNTs has good adsorption characteristic. For $\mathrm{Pb}$, the correlation coefficient $\left(\mathrm{R}^{2}\right)$ is very close to unity and therefore favours Freundlich isotherm model. Comparison of the two isotherms indicates that $\mathrm{Ni}$ was better fitted to model Langmuir while $\mathrm{Cu}, \mathrm{Cd}$. Based on a correlation coefficient, $\mathrm{Pb}, \mathrm{Cr}$ and $\mathrm{Zn}$ are best suited to the Freundlich isotherm model. Table 5 shows the adsorption isotherm of PEG-CNTs. 
Table 5: Isotherm model parameters for adsorption of metal ions onto PEG-CNTs

\begin{tabular}{llllll}
\hline $\begin{array}{l}\text { Isotherm } \\
\text { Parameters }\end{array}$ & $\mathrm{Ni}$ & $\mathrm{Fe}$ & $\mathrm{Cu}$ & $\mathrm{Cd}$ & $\mathrm{Pb}$ \\
\hline Langmuir & & & & & \\
$\mathrm{q}_{\mathrm{e}}(\mathrm{mg} / \mathrm{g})$ & 164.51 & 176.82 & 195.41 & 182.49 & 168.17 \\
$\mathrm{R}^{2}$ & 0.9352 & 0.8971 & 0.8829 & 0.7351 & 0.7246 \\
$\mathrm{R}_{\mathrm{L}}$ & 0.0272 & 0.1604 & 0.0239 & 0.2046 & 0.0127 \\
Freundlich & & & & & \\
$\mathrm{K}_{\mathrm{f}}$ & 0.5372 & 0.0017 & 0.6205 & 0.0524 & 0.3656 \\
$\mathrm{n}$ & 2.3708 & 0.1637 & 2.8563 & 2.5006 & 3.6941 \\
$\mathrm{R}^{2}$ & 0.9872 & 0.9935 & 0.9167 & 0.8887 & 0.9490 \\
\hline
\end{tabular}

According to Table 5, the comparison between the two isotherms indicates that $\mathrm{Ni}, \mathrm{Fe}, \mathrm{Cu}$ and $\mathrm{Pb}$ were better fitted to Freundlich isotherm than Langmuir model due to their correlation coefficients. Also, The value of $n>1$ further supports favourable uptakes for all the heavy metals except Fe. Furthermore, the value of $n>1$ supports favourable uptakes for all the heavy targeted except for Fe. The advantageous uptake implies good electrostatic attraction between the metal ion and PEG-CNT surface. In general, PEG-CNTs adsorbed more than P-CNTs, largely due to chemical modification by the polymer.

\subsection{Adsorption kinetic studies}

In order to interpret and determine the mechanisms of the adsorption processes and the main parameters responsible for the adsorption of the heavy metals kinetic, three models were proposed: Pseudo-first-order, pseudo-second-order and Elovich model as presented in Equ. 7, 8 and 9 , respectively:

$$
\begin{aligned}
& \log \left(\mathrm{q}_{\mathrm{e}}-\mathrm{q}_{\mathrm{t}}\right)=\log \mathrm{q}_{\mathrm{e}}-\frac{\mathrm{K}}{2.303} \mathrm{t} \\
& \frac{1}{\mathrm{q}_{\mathrm{t}}}=\frac{1}{\mathrm{k}_{2} \mathrm{q}_{\mathrm{e}}^{2}}+\frac{\mathrm{t}}{\mathrm{q}_{\mathrm{e}}}
\end{aligned}
$$




$$
\mathrm{q}_{\mathrm{t}}=\frac{1}{\beta} \ln (\alpha \beta)+\frac{1}{\beta} \ln \mathrm{t}
$$

The kinetic parameters for P-CNTs are shown in Table 6.

Table 6: Kinetic parameters of metal ions on P-CNTs

\begin{tabular}{lcccccccccc}
\hline & \multicolumn{3}{c}{ First-order kinetic model } & \multicolumn{3}{c}{ Second-order kinetic model } & \multicolumn{3}{c}{ Elovich model } \\
Metal & $\begin{array}{c}\text { qe, exp } \\
(\mathrm{mg} / \mathrm{g})\end{array}$ & $\begin{array}{c}\mathrm{q}, \mathrm{cal} \\
(\mathrm{mg} / \mathrm{g})\end{array}$ & $\begin{array}{c}\mathrm{k} \\
\left(\mathrm{min}^{1}\right)\end{array}$ & $\mathrm{R}^{2}$ & $\begin{array}{c}\text { qe,cal } \\
(\mathrm{mg} / \mathrm{g})\end{array}$ & $\begin{array}{c}\mathrm{k}_{2} \\
(\mathrm{~g} / \mathrm{mg} . \mathrm{min})\end{array}$ & $\mathrm{R}^{2}$ & $\mathrm{~B}$ & $\alpha$ & $\mathrm{R}^{2}$ \\
\hline $\mathrm{Ni}$ & 2.773 & 0.6226 & 0.0048 & 0.014 & 3.501 & 0.0118 & 0.970 & 1.0770 & 2.0146 & 0.403 \\
$\mathrm{Fe}$ & 90.70 & 77.499 & 0.0838 & 0.782 & 93.46 & 0.0034 & 1.000 & 0.1846 & $232 \times 10^{6}$ & 0.524 \\
$\mathrm{Cu}$ & 6.884 & 0.1508 & 0.0150 & 0.245 & 6.894 & 0.1504 & 1.000 & 1.4341 & 204.52 & 0.722 \\
$\mathrm{~Pb}$ & 10.66 & 0.4656 & 0.0088 & 0.517 & 10.30 & 0.0139 & 0.998 & 0.5582 & 5.9917 & $0 / 894$ \\
$\mathrm{Cd}$ & 0.164 & 0.0159 & 0.0359 & 0.396 & 0.165 & 0.8567 & 0.999 & 27.17 & 0.0501 & 0.801 \\
\hline
\end{tabular}

The pseudo-second-order kinetic model defined the adsorption process more accurately, according to Table 6, and experimental (qe $\mathrm{exp}_{\mathrm{ex}}$ ) fits well with measured (qe $\mathrm{e}_{\mathrm{cal}}$ ). This implies that the steps controlling the rate may be chemisorption. This is accepted with the reports of Yang et al. (2013) and Luo et al. (2013). Table 7 indicates the kinetic parameter of PEG-CNTs.

Table 7: Kinetic parameters of metal ions on PEG-CNTs

\begin{tabular}{cccccccccccc}
\hline & \multicolumn{3}{c}{ First-order kinetic model } & \multicolumn{3}{c}{ Second-order kinetic model } & \multicolumn{3}{c}{ Elovich model } \\
Metal & $\begin{array}{c}\text { qe, exp } \\
(\mathrm{mg} / \mathrm{g})\end{array}$ & $\begin{array}{l}\text { qe, } \\
\text { cal }(\mathrm{mg} / \mathrm{g})\end{array}$ & $\begin{array}{c}\mathrm{k}_{1} \\
\left(\mathrm{~min}^{1}\right)\end{array}$ & $\mathrm{R}^{2}$ & $\begin{array}{l}\mathrm{qe}, \mathrm{cal} \\
(\mathrm{mg} / \mathrm{g})\end{array}$ & $\begin{array}{l}(\mathrm{g} / \mathrm{mg} \\
. \mathrm{min})\end{array}$ & $\mathrm{R}^{2}$ & $\mathrm{~B}$ & $\alpha$ & $\mathrm{R}^{2}$ \\
\hline $\mathrm{Ni}$ & 3.285 & 1.272 & 0.0042 & 0.029 & 3.979 & 0.0135 & 0.954 & 0.1213 & 9235.3 & 0.826 \\
$\mathrm{Fe}$ & 92.43 & 0.340 & 0.0300 & 0.023 & 92.72 & 0.0111 & 1.000 & 0.1192 & 5237.8 & 0.876 \\
$\mathrm{Cu}$ & 6.949 & 0.273 & 0.0111 & 0.361 & 7.148 & 0.0504 & 1.000 & 4.4783 & $6.99 \times 10^{10}$ & 0.879 \\
$\mathrm{~Pb}$ & 10.73 & 1.864 & 0.0083 & 0.284 & 12.09 & 0.0103 & 0.999 & 0.6902 & 25.37 & 0.947 \\
$\mathrm{Cd}$ & 0.169 & 0.011 & 0.0387 & 0.403 & 0.186 & 0.5061 & 0.992 & 38.76 & 0.1771 & 0.903 \\
\hline
\end{tabular}

A similar trend was observed using PEG-CNTs; the kinetic adsorption results were well matched to the kinetic model of second-order compared to the other two models examined. From their $\left(\mathrm{R}^{2}\right)$ principles, that was seen very similar to unity. This shows that PEG-CNTs 
adsorbed the targeted heavy metal compared to P-CNTs due to the addition of a more functional group providing hydrophilic and accelerating the adsorption of battery wastewater metal ions. The formation of bonds between PEG and CNTs may have been electrovalent and covalent in nature and not van der Waal and hydrogen bonds (Sun et al., 2015) which are important for faster adsorption rates compared to P-CNT.

\subsection{Thermodynamic studies}

The thermodynamic constants such as Gibb's free energy $(\Delta \mathrm{G})$, entropy $(\Delta \mathrm{S})$ and enthalpy change $(\Delta \mathrm{H})$ on the adsorption process were calculated. The change in free energy $\left(\Delta \mathrm{G}^{\mathrm{o}}\right)$ was determined using Equ. 10 (Sahika and Ozge, 2014):

$$
\mathrm{G}=-\mathrm{RT} \ln \mathrm{K}
$$

The equilibrium constant was determined using Equ. 11:

$$
\mathrm{K}=\frac{\mathrm{q}_{\mathrm{e}}}{\mathrm{c}_{\mathrm{e}}}
$$

The entropy change $(\Delta \mathrm{S})$ and enthalpy change $(\Delta \mathrm{H})$ were determined using Van't Hoff Equ. 12 (Bankole et al., 2017):

$$
\ln \mathrm{K}=\frac{\Delta \mathrm{S}}{\mathrm{R}}-\frac{\Delta \mathrm{H}}{\mathrm{RT}}
$$

where $\mathrm{R}$ is the universal gas constant $(8.314 \mathrm{~J} / \mathrm{mol} \mathrm{K})$ as presented in Equ. 10 and $12 . \mathrm{T}$ is the absolute temperature $(\mathrm{K})$ and $\mathrm{K}$ is the distribution coefficient. The thermodynamic parameters of the heavy metals by P-CNTs are shown in Table 8 . 
Table 8: Thermodynamic parameters of metal ions from battery wastewater by P-CNTs

\begin{tabular}{|c|c|c|c|c|}
\hline Adsorbate & Temp. $\left({ }^{\circ} \mathrm{K}\right)$ & $\Delta \mathrm{H}\left(\mathrm{kJmol}^{-1}\right)$ & $\Delta \mathrm{S}\left(\mathrm{Jmol}^{-1} \mathrm{k}^{-1}\right)$ & $\Delta \mathrm{G}\left(\mathrm{kJmol}^{-1}\right)$ \\
\hline \multirow[t]{5}{*}{$\mathrm{Ni}$} & 303 & 34.29 & 122.12 & -2.7101 \\
\hline & 313 & & & -3.9312 \\
\hline & 323 & & & -5.1524 \\
\hline & 333 & & & -6.3756 \\
\hline & 343 & & & -7.5947 \\
\hline \multirow[t]{5}{*}{$\mathrm{Fe}$} & 303 & 18.16 & 80.60 & -6.2571 \\
\hline & 313 & & & -7.0631 \\
\hline & 323 & & & -7.8691 \\
\hline & 333 & & & -8.6751 \\
\hline & 343 & & & -9.4811 \\
\hline \multirow[t]{5}{*}{$\mathrm{Cu}$} & 303 & 22.98 & 116.263 & -5.2474 \\
\hline & 313 & & & -6.4100 \\
\hline & 323 & & & -7.5727 \\
\hline & 333 & & & -8.7353 \\
\hline & 343 & & & -9.8979 \\
\hline \multirow[t]{5}{*}{$\mathrm{Cd}$} & 303 & 36.75 & 129.32 & -2.4382 \\
\hline & 313 & & & -3.7315 \\
\hline & 323 & & & -5.0247 \\
\hline & 333 & & & -6.3179 \\
\hline & 343 & & & -7.6112 \\
\hline \multirow[t]{5}{*}{$\mathrm{Pb}$} & 303 & 69.62 & 327.70 & -2.9673 \\
\hline & 313 & & & -3.2950 \\
\hline & 323 & & & -3.6227 \\
\hline & 333 & & & -3.9504 \\
\hline & 343 & & & -4.2781 \\
\hline
\end{tabular}

The positive values of enthalpy $(\Delta \mathrm{H})$ show that the process of adsorption at high temperature was endothermic and more favourable. The positive values of entropy during the adsorption process suggest an increase in randomness at the adsorbent/adsorbent interface. As the temperature increases from 303 to $343 \mathrm{~K}$ which demonstrates spontaneity and feasibility of the adsorption process of the metal ions from battery wastewater, the Gibbs free energy $\left(\Delta \mathrm{G}^{\circ}\right)$ increased. Table 9 depicts the thermodynamic parameters for the PEG-CNTs 
Table 9: Thermodynamic parameters of metal ions adsorption onto PEG-CNTs

\begin{tabular}{|c|c|c|c|c|}
\hline Metal & Temp.(K) & $\Delta \mathrm{H}\left(\mathrm{kJmol}^{-1}\right)$ & $\Delta \mathrm{S}\left(\mathrm{Jmol}^{-1} \mathrm{k}^{-1}\right)$ & $\Delta \mathrm{G}\left(\mathrm{kJmol}^{-1}\right)$ \\
\hline \multirow[t]{5}{*}{$\mathrm{Ni}$} & 303 & 22.09 & 86.62 & -4.7620 \\
\hline & 313 & & & -5.6483 \\
\hline & 323 & & & -6.5345 \\
\hline & 333 & & & -7.4206 \\
\hline & 343 & & & -8.3068 \\
\hline \multirow[t]{5}{*}{$\mathrm{Fe}$} & 303 & 61.80 & 226.40 & -6.8024 \\
\hline & 313 & & & -9.0664 \\
\hline & 323 & & & -11.330 \\
\hline & 333 & & & -13.594 \\
\hline & 343 & & & -15.858 \\
\hline \multirow[t]{5}{*}{$\mathrm{Cu}$} & 303 & 27.52 & 109.46 & -5.6535 \\
\hline & 313 & & & -6.7481 \\
\hline & 323 & & & -7.8428 \\
\hline & 333 & & & -8.9374 \\
\hline & 343 & & & -10.032 \\
\hline \multirow[t]{5}{*}{$\mathrm{Cd}$} & 303 & 25.24 & 96.61 & -4.0367 \\
\hline & 313 & & & -5.0030 \\
\hline & 323 & & & -5.9691 \\
\hline & 333 & & & -6.9352 \\
\hline & 343 & & & -7.9013 \\
\hline \multirow[t]{5}{*}{$\mathrm{Pb}$} & 303 & 83.10 & 302.07 & -8.4304 \\
\hline & 313 & & & -11.451 \\
\hline & 323 & & & -14.471 \\
\hline & 333 & & & -17.492 \\
\hline & 343 & & & -20.513 \\
\hline
\end{tabular}

Table 9 shows similar observations of PEG-CNTs in terms of thermodynamic parameters. Adsorption capacity improvement in PEG-CNTs could be attributed to an increase in pore size, pore-volume, and surface area. This is easily seen in increased enthalpy magnitude at a high temperature which invariably increased the nano-adsorbent activation. In addition, the calculated enthalpy values suggest that the adsorption processes were chemisorption as the values fall within $(-20 \mathrm{~kJ} / \mathrm{mol})$ and $(-80 \mathrm{~kJ} / \mathrm{mol})$ (Yul et al., 2013). The entropy and enthalpy values were positive, showing an increase in the randomness and further confirming the endothermic nature of the adsorption process.

To examine the performance evaluation of PEG/MWCNTs, the adsorption capacity and BET analysis of the PEG/MWCNTs for the removal of metal ions in wastewater has been compared 
with as-prepared CNTs by previous studies as presented in Table 10. The results showed that PEG/MWCNTs was more effective nanoadsorbent. 
Table 10: Comparison of surface area and adsorption capacity (mg/g) of this study with other literature

\begin{tabular}{|c|c|c|c|c|c|c|c|}
\hline Adsorbent & $\begin{array}{l}\text { Condition } \\
\text { parameter }\end{array}$ & $\begin{array}{l}\text { Surface } \\
\text { area } \\
\left(\mathrm{m}^{2} / \mathrm{g}\right)\end{array}$ & $\begin{array}{l}\mathrm{Q}_{\mathrm{m}} \\
(\mathrm{mg} / \mathrm{g})\end{array}$ & $\begin{array}{l}\text { Met } \\
\text { al } \\
\text { ion }\end{array}$ & Isotherm & Kinetic & Reference \\
\hline MWCNTs & $\begin{array}{l}\text { Contact time, } \\
\text { pH, ionic } \\
\text { strength, } \\
\text { temperature }\end{array}$ & 100 & 33.39 & $\mathrm{Cu}$ & $\begin{array}{l}\text { Langmuir, } \\
\text { Freundlich }\end{array}$ & & $\begin{array}{l}\text { Wang et al. } \\
\text { (2013) }\end{array}$ \\
\hline $\begin{array}{l}\text { Sulphonated } \\
\text { polyether/MWC } \\
\text { NTs }\end{array}$ & $\begin{array}{l}\text { Contact time, } \\
\text { pH, ionic } \\
\text { strength, initial } \\
\text { concentration, } \\
\text { pHpzc }\end{array}$ & 54.025 & 54.054 & $\mathrm{~Pb}$ & $\begin{array}{l}\text { Langmuir, } \\
\text { Freundlich }\end{array}$ & $\begin{array}{l}\text { Pseudo-first-order, } \\
\text { pseudo-second- } \\
\text { order }\end{array}$ & $\begin{array}{l}\text { Rashid et al. } \\
\text { (2019) }\end{array}$ \\
\hline $\begin{array}{l}\text { Magnetic } \\
\text { MWCNTs }\end{array}$ & $\begin{array}{l}\text { Contact time, } \\
\mathrm{pH} \text {, dosage }\end{array}$ & & $\begin{array}{l}\mathrm{Pb} \\
(67.25), \\
\mathrm{Zn}(3.759)\end{array}$ & $\begin{array}{l}\mathrm{Pb} \\
\mathrm{Zn}\end{array}$ & $\begin{array}{l}\text { Langmuir, } \\
\text { Freundlich }\end{array}$ & $\begin{array}{l}\text { Pseudo-first-order, } \\
\text { pseudo-second- } \\
\text { order }\end{array}$ & $\begin{array}{l}\text { Jiang et al. } \\
(2015)\end{array}$ \\
\hline $\begin{array}{l}\text { Acid modified } \\
\text { MWCNTs }\end{array}$ & $\begin{array}{l}\mathrm{pH} \text {, dosage, } \\
\text { contact time, } \\
\text { initial } \\
\text { concentration, } \\
\text { temperature }\end{array}$ & 288.45 & 26.88 & $\mathrm{Cd}$ & $\begin{array}{l}\text { Langmuir, } \\
\text { Freundlich }\end{array}$ & $\begin{array}{l}\text { Pseudo-first-order, } \\
\text { pseudo-second- } \\
\text { order, intraparticle } \\
\text { diffusion, Boyd } \\
\text { equation }\end{array}$ & $\begin{array}{l}\text { Akl and } \\
\text { Abou- } \\
\text { Elanwar } \\
(2015)\end{array}$ \\
\hline $\begin{array}{l}\text { Triethylene } \\
\text { glycol/CNTs }\end{array}$ & $\begin{array}{l}\mathrm{pH}, \text { dosage, } \\
\text { contact time }\end{array}$ & 179.06 & 122.1 & $\mathrm{~Pb}$ & $\begin{array}{l}\text { Langmuir, } \\
\text { Freundlich }\end{array}$ & $\begin{array}{l}\text { Pseudo-first-order, } \\
\text { pseudo-second- } \\
\text { order, intraparticle } \\
\text { diffusion }\end{array}$ & $\begin{array}{l}\text { Al-Omar et } \\
\text { al. }(2016)\end{array}$ \\
\hline $\begin{array}{l}\text { Ethylenediamin } \\
\text { e/MWCNTs }\end{array}$ & $\begin{array}{l}\mathrm{pH} \text {, contact time, } \\
\text { initial } \\
\text { concentration, } \\
\text { temperature }\end{array}$ & 101.24 & 25.70 & $\mathrm{Cd}$ & $\begin{array}{l}\text { Langmuir, } \\
\text { Freundlich }\end{array}$ & $\begin{array}{l}\text { Pseudo-first-order, } \\
\text { pseudo-second- } \\
\text { order }\end{array}$ & $\begin{array}{l}\text { Vukovicet al. } \\
\text { (2010) }\end{array}$ \\
\hline MWCNTs & $\begin{array}{l}\mathrm{pH}, \text { ionic } \\
\text { strength, } \\
\text { temperature }\end{array}$ & & 4.2239 & $\mathrm{Cu}$ & $\begin{array}{l}\text { Langmuir, } \\
\text { Freundlich }\end{array}$ & & $\begin{array}{l}\text { Sheng et al. } \\
(2010)\end{array}$ \\
\hline $\mathrm{NH}_{2} / \mathrm{MWCNTs}$ & $\begin{array}{l}\text { Concentration, } \\
\text { temperature }\end{array}$ & & 21.01 & $\mathrm{Cu}$ & $\begin{array}{l}\text { Langmuir, } \\
\text { Freundlich }\end{array}$ & $\begin{array}{l}\text { Pseudo-first-order, } \\
\text { Pseudo-second- } \\
\text { order }\end{array}$ & $\begin{array}{l}\text { Salehi et al. } \\
\text { (2012) }\end{array}$ \\
\hline PAMAM/CNT & $\begin{array}{l}\mathrm{pH} \text {, dosage, } \\
\text { initial } \\
\text { concentration, } \\
\text { ionic strength }\end{array}$ & 93.60 & 17.54 & $\mathrm{~Pb}$ & $\begin{array}{l}\text { Langmuir, } \\
\text { Freundlich }\end{array}$ & & $\begin{array}{l}\text { Ren et al. } \\
(2011)\end{array}$ \\
\hline PEG-CNTs & $\begin{array}{l}\text { Contact time. } \\
\text { dosage, } \\
\text { temperature }\end{array}$ & 970.81 & $\begin{array}{l}\mathrm{Ni} \\
(164.51), \\
\mathrm{Fe} \\
(176.82), \\
\mathrm{Cu} \\
(195.41), \\
\mathrm{Cd} \\
(182.49), \\
\mathrm{Pb} \\
(168.17)\end{array}$ & $\begin{array}{l}\mathrm{Ni}, \\
\mathrm{Fe}, \\
\mathrm{Cu}, \\
\mathrm{Cd}, \\
\mathrm{Pb}\end{array}$ & $\begin{array}{l}\text { Langmuir, } \\
\text { Freundlich }\end{array}$ & $\begin{array}{l}\text { Pseudo-first-order, } \\
\text { pseudo-second- } \\
\text { order, Elovich }\end{array}$ & Present study \\
\hline
\end{tabular}




\section{Conclusion}

In summary, CNTs were successfully prepared in a CVD reactor by deposition of acetylene gas on the support of bimetallic Fe-Ni / kaolin. The as-synthesized CNTs were processed by acid mixing process followed by polyethylene glycol functionalization. The three nanomaterials have also been characterized by various analytical techniques and adsorption behaviour of purified CNTs and PEG-modified CNTs for removing selected heavy metals (Ni, $\mathrm{Fe}, \mathrm{Cu}, \mathrm{Cd}$ and $\mathrm{Pb}$ ) from industrial wastewater battery were also performed, The results of the characterization showed that PEG was successfully embedded and encapsulated on the lattice layer of CNTs and the surface area was also improved by the steps of PEG functionalization. Contact time $(90 \mathrm{~min})$, adsorbent dosage $(0.3 \mathrm{~g} / 50 \mathrm{~mL})$ and temperature $\left(60{ }^{\circ} \mathrm{C}\right)$ were the best conditions for removing the metal ions from battery wastewater. The descending order of the metal ions removal from battery wastewater was $\mathrm{Cu}>\mathrm{Fe}>\mathrm{Pb}>\mathrm{Cd}>\mathrm{Ni}$, irrespective of the nano-adsorbents. The experimental adsorption of $\mathrm{Ni}$ by the two materials confirmed to Langmuir model isotherm while equilibrium data of other metals such as $\mathrm{Ni}, \mathrm{Fe}, \mathrm{Cu}$ and $\mathrm{Pb}$ were better described by Freundlich isotherm based on their correlation coefficient $\left(\mathrm{R}^{2}\right)$.

Additionally, nano-adsorbent equilibrium adsorption data for the selected metals followed the order of pseudo-second-order kinetics > Elovich model > pseudo-first-order kinetic model. The determined thermodynamics parameters indicate endothermic, feasible and spontaneous nature of the adsorption of heavy metals from the wastewater. Although both P-CNTs and PEG-CNTs had high efficiencies in removing heavy metals from battery wastewater, PEG-CNTs were found to be highly effective in removing target heavy metals compared to P-CNTs. 


\section{Data Availability Statement}

The datasets produced during and/or analysed during the present study are readily available from the corresponding author on reasonable request.

\section{Conflicting Interests Declaration}

The author(s) declared no potential conflicts of interest.

\section{Acknowledgements}

This work was financially supported by Tertiary Education Trust Fund, Nigeria (TETFUND/FUTMINNA/NRF/2014/01) and African Centre of Excellence on Mycotoxins, Federal University of Technology, Minna, Nigeria.

\section{Authors Contributions}

All authors contributed to the study conception and design. Material preparation, data collection and analysis were performed by [Ambali Saka Abdulkareem], [Hamzat Wasiu], [Jimoh Oladejo Tijani], [Mercy Temitope Bankole], [Titus Chinedu Egbosiuba], [Abubakre Oladiran Kamardeen] and [Mustapha Saheed]. The first draft of the manuscript was written by [Hamzat Wasiu] and all authors commented on previous versions of the manuscript. All authors read and approved the final manuscript. 


\section{References}

Aamir, A., Adnan, M.A. Tahar, L., Mohammed, J. Al-Marri, M. Mustafa, A.S.(2016) Heavy Metal Removal From Aqueous Solution By Advanced Carbon Nanotubes: Critical Review of Adsorption Applications. Separation and Purification Technology. 157,141164.

Abdulkareem, A.S., Kariim, I., Bankole, M.T., Tijani, J.O \& Olu, S.C. (2017). Synthesis and Characterization of Tri-metallic Fe-Co-Ni Catalyst Supported on $\mathrm{CaCO}_{3}$ for Multiwalled Carbon Nanotubes Growth via Chemical Vapor Depostion technique. Arabian Journal of Science and Engineering, 2,1-25.

Ahmed, D.S., Adawiya, J., Haiderb, M.R., Mohammad, A.(2016) Comparison of Functionalization of multiwalled carbon nanotubes treated by oil olive and nitric acid and their characterization. Advancements in Renewable Energy and Clean Environment, 36, 1111-1118.

Akl, M. A., \& Abou-Elanwar, A. M. (2015). Adsorption studies of cd (II) from water by acid modified multiwalled carbon nanotubes. Journal of Nanomedicine and Nanotechnology, 6(6), 1.

Aliyu, A. (2016). Development of A Suitable Bimetallic (Fe-Co) Catalyst On Kaolin Support For Carbon Nanotube Synthesis.MSc thesis. Niger State: Federal University of Technology,

Al-Obaidi, M. A., Li, J. P., Kara-Zaitri, C., \& Mujtaba, I. M. (2017). Optimisation of reverse osmosis based wastewater treatment system for the removal of chlorophenol using genetic algorithms. Chemical Engineering Journal, 316, 91-100.

AlOmar, M. K., Alsaadi, M. A., Hayyan, M., Akib, S., Ibrahim, R. K., \& Hashim, M. A. (2016). Lead removal from water by choline chloride based deep eutectic solvents functionalized carbon nanotubes. Journal of Molecular Liquids, 222, 883-894.

Angulakshmi, V. K. (2015). Effect of Synthesis Temperature on the Growth of Multiwalled Carbon Nanotubes From Zeamays Oil as evidenced by Structural, Raman and XRD Analyses. .8,1-7.

Bankole, M.T., Abdulkareem, A.S. Tijani, J.O., Ochigbo, S.S., Afolabi, A.S. Roos, W.D.(2017a) Chemical oxygen demand removal from electroplating wastewater by purified and polymer functionalized carbon nanotubes adsorbents. Water Resources and industries, 18, 33-50.

Bankole, M.T., Abdulkareem, A.S. Tijania, J.O., Ochigboa, S.S., Afolabi, A.S. Roos, W.D. (2017b) Chemical oxygen demand removal from electroplating wastewater by purified and polymer functionalized carbon nanotubes adsorbents. Water Resources and Industries. 18, 33 - 50.

Chen Z., Lina, S., Jianhua, D., Mallavarapu, Megharaj, R.N.(2014): Functional kaolinite supported $\mathrm{Fe} / \mathrm{Ni}$ nanoparticles for simultaneous catalytic remediation of mixed contaminants (lead and nitrate) from wastewater. Journal of Colloid and Interface Science.428,302-307.

Chungsying, L.C. (2016) Removal of nickel(II) from aqueous solution by carbon nanotubes Chemical Technology and Biotechnology, 81, 1932-1940. 
Dawodu, A. F., Kovo, A., Mark, A (2012) Equilibrium Isotherm Studies on the Batch Sorption of Copper (II) ions from Aqueous Solution unto Nsu Clay. International Journal of Scientific and Engineering Research 3.1-7.

Egbosiuba, T.C., Abdulkareem, A.S., Kovo, A.S., Afolabi, E.A., Tijani, J.O., Auta, M., Roos, W.D. (2020a). Ultrasonic enhanced adsorption of methylene blue onto the optimized surface area of activated carbon: Adsorption isotherm, kinetics and thermodynamics. Chemical Engineering Research and Design 153, 315-336.

Egbosiuba, T.C., Abdulkareem, A.S., Kovo, A.S., Afolabi, E.A., Tijani, J.O., Bankole, M.T., Bo, S., Roos, W.D. (2021a). Adsorption of Cr(VI), Ni(II), Fe(II) and Cd(II) ions by KIAgNPs decorated MWCNTs in a batch and fixed bed process. Scientific Reports 11, $1-20$.

Egbosiuba, T.C., Abdulkareem, A.S., Kovo, A.S., Afolabi, E.A., Tijani, J.O., Roos, W.D. (2020b). Enhanced adsorption of As(V) and Mn(VII) from industrial wastewater using multi-walled carbon nanotubes and carboxylated multi-walled carbon nanotubes. Chemosphere 254, 126780.

Egbosiuba, T.C., Abdulkareem, A.S., Tijani, J.O., Ani, J.I., Krikstolaityte, V., Srinivasan, M., Veksha, A., Lisak, G. (2021b). Taguchi optimization design of diameter-controlled synthesis of multi walled carbon nanotubes for the adsorption of $\mathrm{Pb}$ (II) and $\mathrm{Ni}$ (II) from chemical industry wastewater. Chemosphere 128937.

El-Enein, S.A., Okbah, M.A., Hussain, S.G., Soliman, N.F., Ghounam, H.H. (2020). Adsorption of Selected Metals Ions in Solution Using Nano-Bentonite Particles: Isotherms and Kinetics. Environ. Process. 7, 463-477.

El-Nemr, M.A., Abdelmonem, N.M., Ismail, I.M.A., Ragab, S., El Nemr, A. (2020). Ozone and Ammonium Hydroxide Modification of Biochar Prepared from Pisum sativum Peels Improves the Adsorption of Copper (II) from an Aqueous Medium, Environmental Processes. 7, 973-1007.

Farghali, A.A., Abdel Tawab, H.A., Abdel Moaty, S.A. (2017) Functionalization of acidified multi-walled carbon nanotubes for removal of heavy metals in aqueous solutions. $J$ Nanostruct Chem 7, 101-111

Fenglian, F., and Qi, W. (2010) Removal of heavy metal ions from wastewaters: A review. Journal of Environmental Management, 92, 112-119

G.C. Chen, X.Q. Shan, Y.S. Wang, Z.G. Pei, X.E. Shen, B. Wen, G. Owens, (2008) Effects of copper, lead, and cadmium on the sorption and desorption of atrazine onto and from carbon nanotubes, Environ. Sci. Technol. 42. 8297-8302

GilPavas, E., Dobrosz-Gómez, I., \& Gómez-García, M. Á. (2017). Coagulation-flocculation sequential with Fenton or Photo-Fenton processes as an alternative for the industrial textile wastewater treatment. Journal of environmental management, 191, 189-197.

Hamzat WA, Abdulkareem AS, Bankole MT, Tijani JO, Kovo AS, Abubakre OK (2019). Adsorption studies on the treatment of battery wastewater by purified carbon nanotubes (P-CNTs) and polyethylene glycol carbon nanotubes (PEGCNTs). Journal of Environmental Science and Health, Part A,

Hanaei, H. (2013)The Interaction Effects of Synthesis Reaction Temperature and Catalyst Loading on Carbon Nanotubes (CNTs) Yield, International Journal of Engineering \& Technology Sciences (IJETS) 1 (1): 24-31 
Hassan, I. O. (2016). Development of A Suitable Bimetallic (Fe-Co) Catalyst On Kaolin Support For Carbon Nanotube Synthesis. Niger State. MSc thesis .Federal University of Technology,Minna,Niger State.

Heithmar, E. M. \& Pergantis, E (2010) Characterizing concentrations and size distributions of metal-containing nanoparticles in waste water. U.s. Environmental protection agency, washington, dc, epa/600/r-10/117,

Hsieh, C.-T., Lin, Y.-T., Chen, W.-Y., Wei, J.-L. (2009. Parameter setting on growth of carbon nanotubes over transition metal/alumina catalysts in a fluidized bed reactor. Powder.Technol. 192, 16-22

Igwegbe, C.A., Onukwuli, O.D., Ighalo, J.O., Okoye, P.U. (2020). Adsorption of Cationic Dyes on Dacryodes edulis Seeds Activated Carbon Modified Using Phosphoric Acid and Sodium Chloride. Environ. Process. 7, 1151-1171.

Janković, B., Manić, N., Dodevski, V., Radović, I., Pijović, M., Katnić, Đ., \& Tasić, G. (2019). Physico-chemical characterization of carbonized apricot kernel shell as precursor for activated carbon preparation in clean technology utilization. Journal of Cleaner Production, 236, 117614.

Jiang, L., Yu, H., Zhou, X., Hou, X., Zou, Z., Li, S., Li, C. and Yao, X., 2016. Preparation, characterization, and adsorption properties of magnetic multi-walled carbon nanotubes for simultaneous removal of lead (II) and zinc (II) from aqueous solutions. Desalination and Water Treatment, 57(39), pp.18446-18462.

Jiaxing, L., Shuyu, C., Guodong, S., Jun, H.,Xiaoli, T., Xiangke, W.(2011) Effect of surfactants on $\mathrm{Pb}$ (II) adsorption from aqueous solutions using oxidized multiwall carbon nanotubes. Chemical Engineering Journal, 166, 551 - 558.

Kariim I, Abdulkareem, A.S., Abubakre, Oladiran, K., Aliyu, A., Mohammed, I.A., Hamidu, A.(2016). Characterization and antibacterial activity of nickel ferrite doped $\alpha$-alumina nanoparticle. Engineering Science and Technology, an International Journal, 1,1-7.

Kausar, A \& Siddiq, M (2016) Polyurethane/poly(ethylene-co-ethyl acrylate) and functional carbon black-based hybrids: Physical properties and shape memory behaviour. Applied Polymer, 133, 20-32.

Li, X., Jin, X., Zhao, N., Angelidaki, I., \& Zhang, Y. (2017). Novel bio-electro-Fenton technology for azo dye wastewater treatment using microbial reverse-electrodialysis electrolysis cell. Bioresource Technology, 228, 322-329.

Lokhande, R.S.; Singare, P.U.; Pimple, D.S. (2012) Study on physico-chemical parameters of waste water effluents from Taloja industrial area of Mumbai, India. Int. J. Ecosyst. 1, $1-9$.

Lyuke, H. C., Abdulkareem, P. A., \& Afolabi, A. S. (2010). optimising carbon nanotube continuous production in a swirled floating catalyst chemical vapour deposition reactor. .Journall of Chemical and Metallurgical Engineering, Vol 2,217-230.

Ma, A., Abushaikha, A., Allen, S. J., \& McKay, G. (2019). Ion exchange homogeneous surface diffusion modelling by binary site resin for the removal of nickel ions from wastewater in fixed beds. Chemical Engineering Journal, 358, 1-10.

Mohamed, A., \& Robert, B. (2012). Synthesis and characterization of multi-walled carbon nanotube modified with octadecylamine and polyethylene glycol. Arabian Journal of Chemistry, 10,921-927. 
Mohammad, H., M. M., Anil, K., \& Behzad, H. (2014). Removal of noxious Cr (VI) ions using single-walled carbon nanotubes and multi-walled carbon nanotubes,. Chemical Engineering Journa, 1.279, 344-352.

Mudzielwana, R., Gitari, W.M., Ndungu, P. (2019). Removal of As(III) from Synthetic Groundwater Using Fe-Mn Bimetal Modified Kaolin Clay: Adsorption Kinetics, Isotherm and Thermodynamics Studies. Environ. Process. 6, 1005-1018.

Muhammad, H., Al-Malack \& Abdullahi, A.B.(2016). Adsorption of heavy metals using activated carbon produced from municipal organic solid waste. Desalination and Water Treatment, 57.832-841.

NESREA (2011) Guidelines for drinking water.693-727.

Nessim, G. D., Matteo, S., Desire, L. Plata, K, P., Brien, A., John, H., Eric, R.M., Christopher, M.. Reddy, Philip, M. G., Carl, V. T, (2010). Precursor gas chemistry determines the crystallinity of carbon nanotubes synthesized at low temperature. Carbon, 39, 806-810.

Özsin, G., Kılıç, M., Apaydın-Varol, E., \& Pütün, A. E. (2019). Chemically activated carbon production from agricultural waste of chickpea and its application for heavy metal adsorption: equilibrium, kinetic, and thermodynamic studies. Applied Water Science, 9(3), 56.

Prazeres, A. R., Luz, S., Fernandes, F., \& Jeronimo, E. (2020). Cheese wastewater treatment by acid and basic precipitation: Application of $\mathrm{H}_{2} \mathrm{SO}_{4}, \mathrm{HNO}_{3}, \mathrm{HCl}, \mathrm{Ca}(\mathrm{OH})_{2}$ and $\mathrm{NaOH}$. Journal of Environmental Chemical Engineering, 8(2), 103556.

Rahmani-Sani, A., Singh, P., Raizada, P., Lima, E.C., Anastopoulos, I., Giannakoudakis, D.A., Sivamani, S., Dontsova, T.A. and Hosseini-Bandegharaei, A., 2020. Use of chicken feather and eggshell to synthesize a novel magnetized activated carbon for sorption of heavy metal ions. Bioresource Technology, 297, 122452.

Rao, R.A.K., Kashifuddin, M. (2014). Kinetics and isotherm studies of Cd(II) adsorption from aqueous solution utilizing seeds of bottlebrush plant (Callistemon chisholmii). Appl Water Sci 4, 371-383.

Rashid, J., Azam, R., Kumar, R., Ahmad, M., Rehman, A., \& Barakat, M. A. (2019). Sulfonated polyether sulfone reinforced multiwall carbon nanotubes composite for the removal of lead in wastewater. Applied Nanoscience, 9(8), 1695-1705.

Ren, X., Shao, D., Yang, S., Hu, J., Sheng, G., Tan, X., \& Wang, X. (2011). Comparative study of $\mathrm{Pb}$ (II) sorption on XC-72 carbon and multi-walled carbon nanotubes from aqueous solutions. Chemical engineering journal, 170(1), 170-177.

Salehi, E., Madaeni, S.S., Rajabi, L., Vatanpour, V., Derakhshan, A.A., Zinadini, S., Ghorabi, S. and Monfared, H.A., 2012. Novel chitosan/poly (vinyl) alcohol thin adsorptive membranes modified with amino functionalized multi-walled carbon nanotubes for $\mathrm{Cu}$ (II) removal from water: preparation, characterization, adsorption kinetics and thermodynamics. Separation and Purification Technology, 89, 309-319.

Salih, S.S., Ghosh, T.K. (2018). Preparation and Characterization of Chitosan-Coated

Diatomaceous Earth for Hexavalent Chromium Removal. Environ. Process. 5, 23-39.

Sheng, G., Li, J., Shao, D., Hu, J., Chen, C., Chen, Y., \& Wang, X. (2010). Adsorption of copper (II) on multiwalled carbon nanotubes in the absence and presence of humic or fulvic acids. Journal of Hazardous Materials, 178(1-3), 333-340.

Shirazi, Y. M. (2012). Effects of different carbon precursors on synthesis of multiwall carbon nanotubes: Purification and Functionalization. The Online Journal of Science and Technology.257,7359-7367. 
Tessonnier, J., \& Sheng Su, D. (2011). Recent Progress on the Growth Mechanism of Carbon Nanotubes: A Review DOI: 10.1002/cssc.201100175.5. .PP 1-25.

Tijani, J. O., Momoh, U. O., Salau, R. B., Bankole, M. T., Abdulkareem, A. S., \& Roos, W. D. (2019). Synthesis and characterization of $\mathrm{Ag}_{2} \mathrm{O} / \mathrm{B}_{2} \mathrm{O}_{3} / \mathrm{TiO}_{2}$ ternary nanocomposites for photocatalytic mineralization of local dyeing wastewater under artificial and natural sunlight irradiation. Environmental Science and Pollution Research, 26(19), 1994219967.

Vuković, G. D., Marinković, A. D., Čolić, M., Ristić, M. Đ., Aleksić, R., Perić-Grujić, A. A., \& Uskoković, P. S. (2010). Removal of cadmium from aqueous solutions by oxidized and ethylenediamine-functionalized multi-walled carbon nanotubes. Chemical Engineering Journal, 157(1), 238-248.

Wang, J., Li, Z., Li, S., Qi, W., Liu, P., Liu, F., Ye, Y., Wu, L., Wang, L. and Wu, W., 2013. Adsorption of $\mathrm{Cu}$ (II) on oxidized multi-walled carbon nanotubes in the presence of hydroxylated and carboxylated fullerenes. Plos one, 8(8), e72475.

WHO (2011): Guidelines for drinking water.

Xiangtao, W., Yifei , G., Li, Y., Meihua , H., Jing, Z., and Xiaoliang, C.(2012) Nanomaterials as Sorbents to Remove Heavy Metal Ions in Wastewater Treatment. Environment and Analytical Toxicology. 2, 1-7.

Yesil, S \& Bayram,G (2011) Effect of carbon purification on the electrical and mechanical properties of polyethylene terephthalate composites with carbon nanotubes in low concentration. Journal of applied polymer science. 2 , 13-27.

Yu1, F., Yanqing, W., Jie, M., Chi, Z.,(2013) Adsorption of lead on multi-walled carbon nanotubes with different outer diameters and oxygen contents: Kinetics, isotherms and thermodynamics. Journal of Environmental Sciences 25, 193 -205.

Yuanyuan, G. Z. (2014). Sulfonated multi-walled carbon nanotubes for the removal of copper (II) from aqueous solutions. Journal of Industrial and Engineering Chemistry, 20,17651771.

Zhan, J., Li, Z., Yu, G., Pan, X., Wang, J., Zhu, W., Han, X. and Wang, Y., 2019. Enhanced treatment of pharmaceutical wastewater by combining three-dimensional electrochemical process with ozonation to in situ regenerate granular activated carbon particle electrodes. Separation and Purification Technology, 208, 12-18.

Zhang, H., Niu, Z., Liu, Z., Wen, Z., Li, W., Wang, X., \& Wu, W. (2015) Equilibrium, kinetic and thermodynamic studies of adsorption of Th(IV) from aqueous solution onto kaolin, Journal of Radioanalytical and Nuclear Chemistry. 303:87-97.

Zhang, L., Lv, P., He, Y., Li, S., Chen, K., \& Yin, S. (2020). Purification of chlorine-containing wastewater using solvent extraction. Journal of Cleaner Production, 273, 122863. 

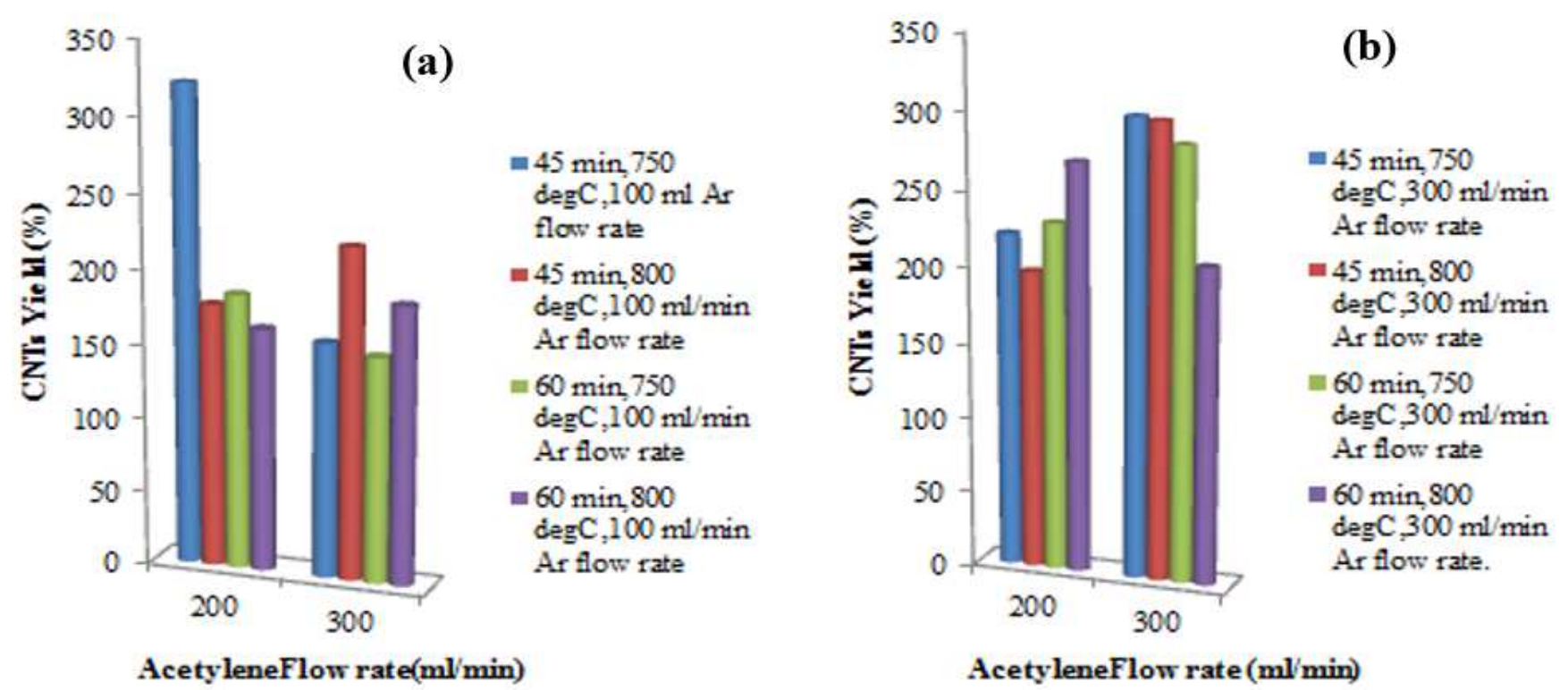

AcetyleneFlow rate (ml/min)

Figure 1

Effect of acetylene flow rate on CNTs yield at argon flow rates of (a) $100 \mathrm{ml} / \mathrm{min}$, and (b) $300 \mathrm{ml} / \mathrm{min}$
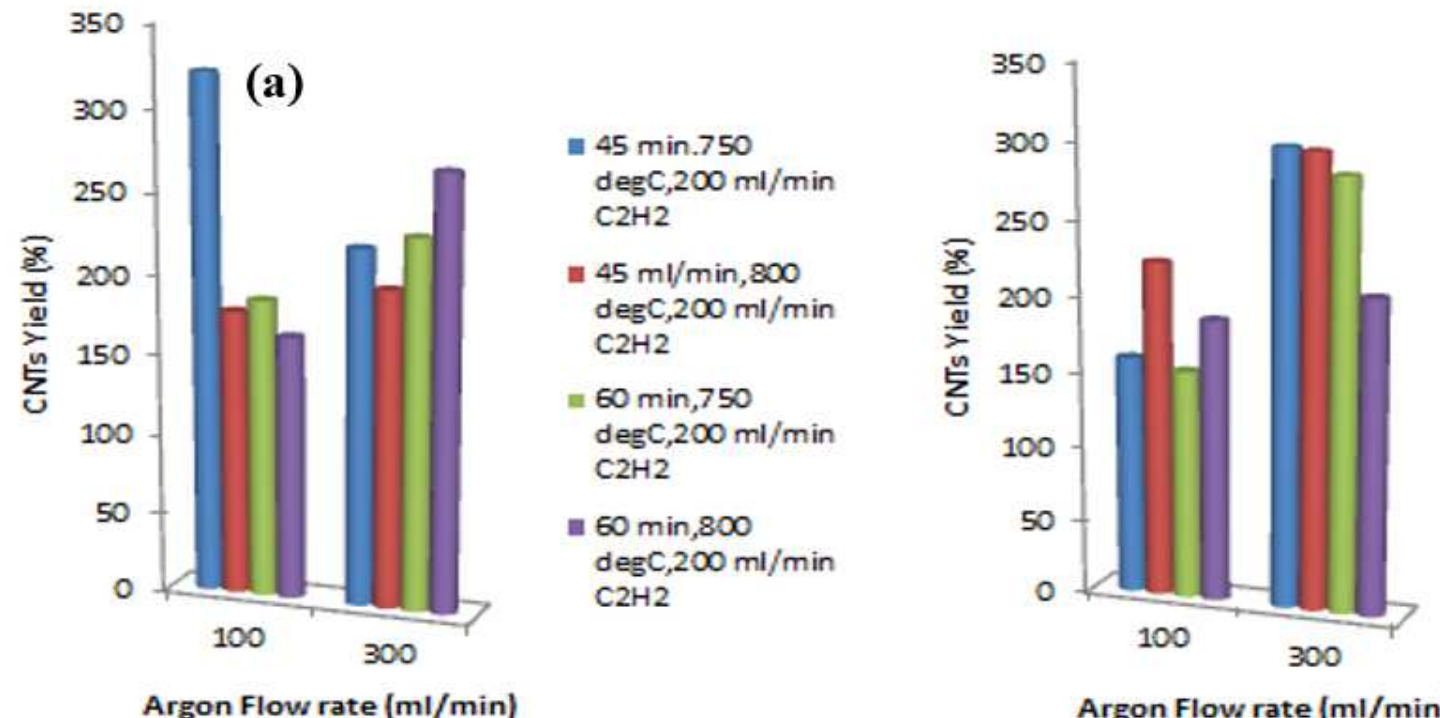

(b)

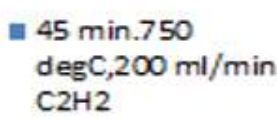

= $45 \mathrm{ml} / \mathrm{min}, 800$ $\operatorname{deg} \mathrm{C}, 200 \mathrm{ml} / \mathrm{min}$ $\mathrm{C}_{2} \mathrm{H}_{2}$

$=60 \mathrm{~min}, 750$ $\operatorname{deg} \mathrm{C}, 200 \mathrm{ml} / \mathrm{min}$ $\mathrm{C} 2 \mathrm{H} 2$

an $60 \mathrm{~min}, 800$ $\operatorname{deg} \mathrm{C}, 200 \mathrm{ml} / \mathrm{min}$ $\mathrm{C} 2 \mathrm{H}_{2}$

Argon Flow rate $[\mathrm{ml} / \mathrm{min})$

Argon Flow rate ( $\mathrm{ml} / \mathrm{min})$

= $45 \mathrm{~min}, 750$ $\operatorname{deg} \mathrm{C}, 300 \mathrm{ml} / \mathrm{in}$ $\mathrm{C} 2 \mathrm{H} 2$

= $45 \mathrm{~min}, 800$ $\operatorname{deg} C, 3 \infty \mathrm{ml} / \mathrm{min}$ $\mathrm{C} 2 \mathrm{H} 2$

$1160 \mathrm{~min}, 750$ $\operatorname{deg} \mathrm{C}, 300 \mathrm{ml} / \mathrm{min}$ $\mathrm{C} 2 \mathrm{H}_{2}$

$=60 \mathrm{~min}, 800$ $\operatorname{deg} \mathrm{C}, 300 \mathrm{ml} / \mathrm{min}$ $\mathrm{C} 2 \mathrm{H} 2$

\section{Figure 2}

Effect of argon flow rate on CNTs yield at an acetylene flow rate of (a) $200 \mathrm{ml} / \mathrm{min}$, and (b) $300 \mathrm{ml} / \mathrm{min}$ 


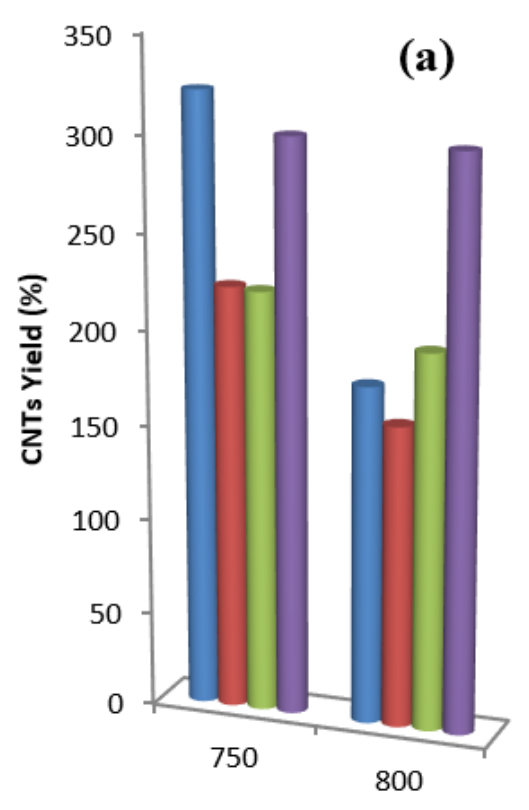

Temperature $\left({ }^{\circ} \mathrm{C}\right)$

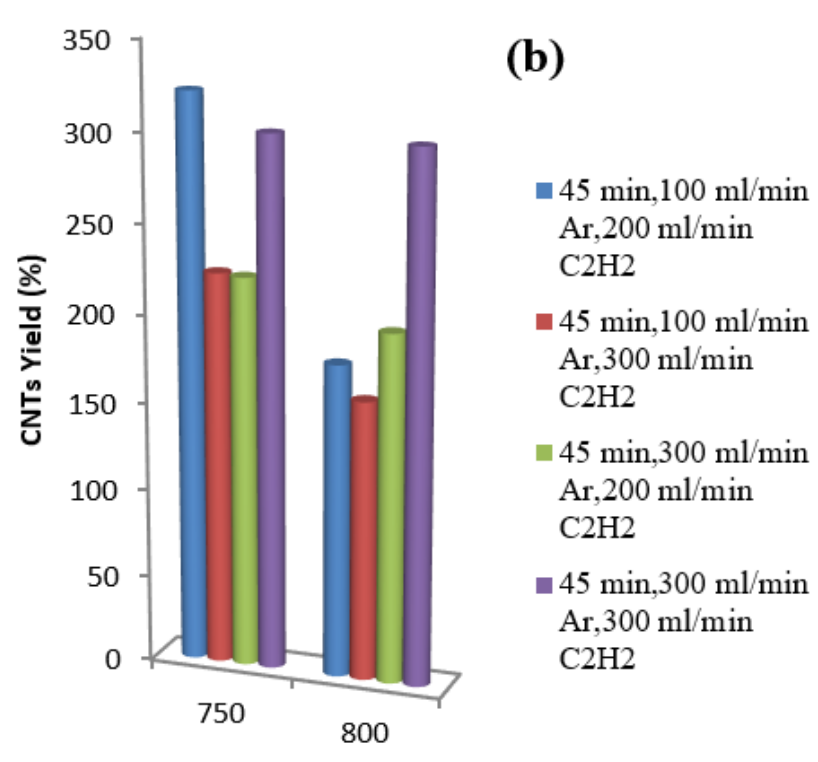

Temperature $\left({ }^{\circ} \mathrm{C}\right)$
$\mathrm{Ar}, 200 \mathrm{ml} / \mathrm{min}$

$\mathrm{C} 2 \mathrm{H} 2$

$\mathrm{Ar}, 300 \mathrm{ml} / \mathrm{min}$ $\mathrm{C} 2 \mathrm{H} 2$

$\mathrm{Ar}, 200 \mathrm{ml} / \mathrm{min}$ $\mathrm{C} 2 \mathrm{H} 2$

$\mathrm{Ar}, 300 \mathrm{ml} / \mathrm{min}$ $\mathrm{C} 2 \mathrm{H} 2$

\section{Figure 3}

Effect of temperature on CNTs yield at (a) 45 min growth time (b) 60 min growth time

(a)

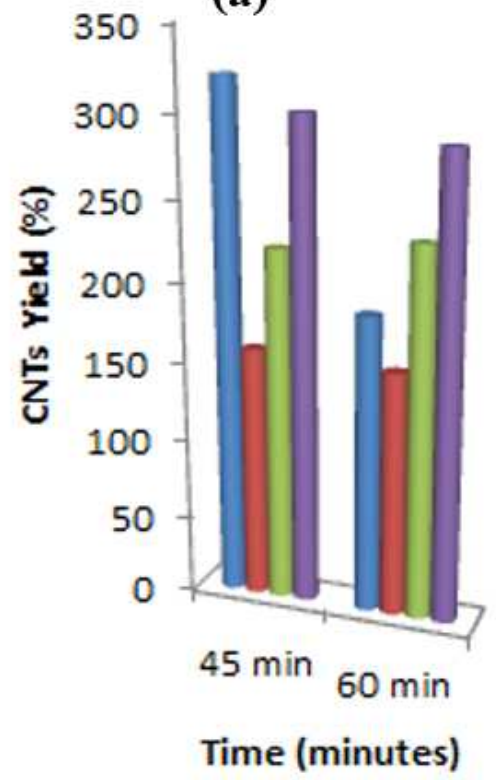

$45 \mathrm{~min}, 100 \mathrm{ml} / \mathrm{min}$ $\mathrm{Ar}, 200 \mathrm{ml} / \mathrm{min} \mathrm{C} 2 \mathrm{H} 2$

- $45 \mathrm{~min}, 100 \mathrm{ml} / \mathrm{min}$ $\mathrm{Ar}, 300 \mathrm{ml} / \mathrm{min} \mathrm{C} 2 \mathrm{H} 2$

$45 \mathrm{~min}, 300 \mathrm{ml} / \mathrm{min}$

$\mathrm{Ar}, 200 \mathrm{ml} / \mathrm{min} \mathrm{C} 2 \mathrm{H} 2$

- $45 \mathrm{~min}, 300 \mathrm{ml} / \mathrm{min}$ $\mathrm{Ar}, 300 \mathrm{ml} / \mathrm{min} \mathrm{C} 2 \mathrm{H} 2$ (b)

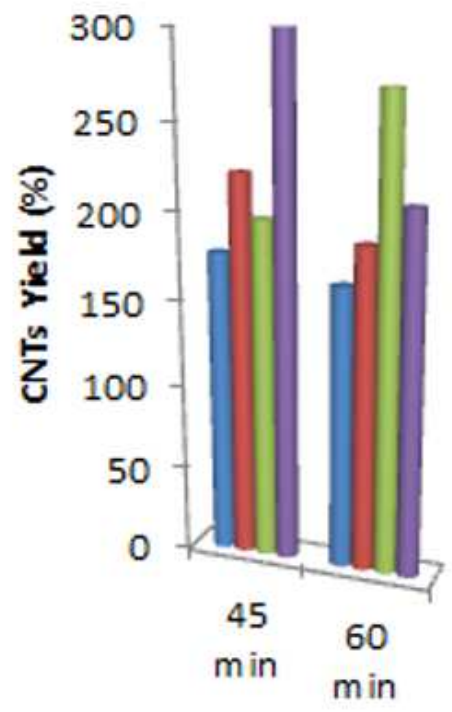

Time (minutes)

\section{Figure 4}

Effect of time on CNT yield at the temperature of (a) $700 \mathrm{oC}$, and (b) $750 \mathrm{oC}$ 


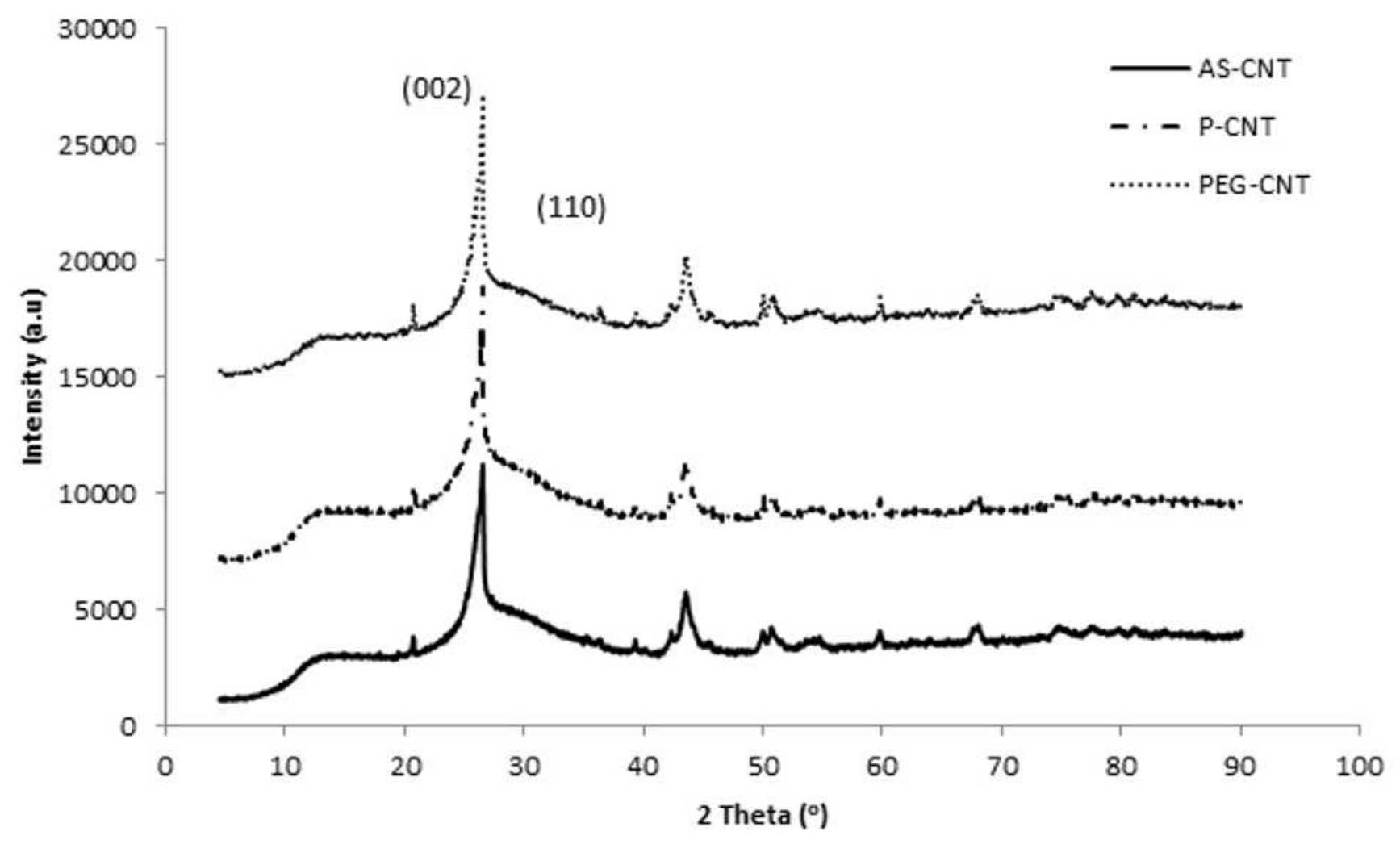

Figure 5

XRD patterns for as-synthesized, purified, and PEG-functionalized CNTs

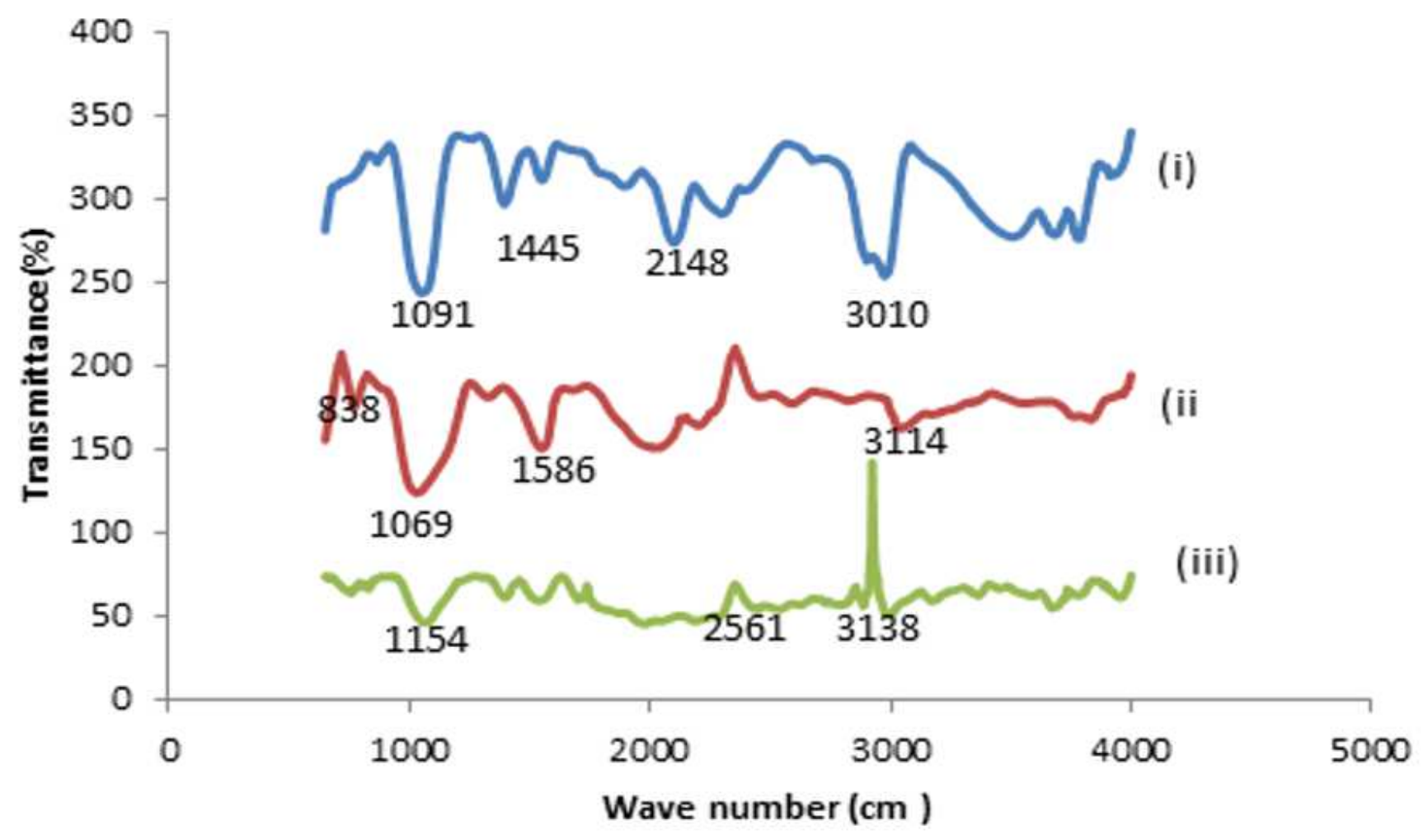

Figure 6 
FTIR spectra of (i) As-synthesized CNTs, (ii) Purified CNTs, and (iii) PEG functionalized CNTs

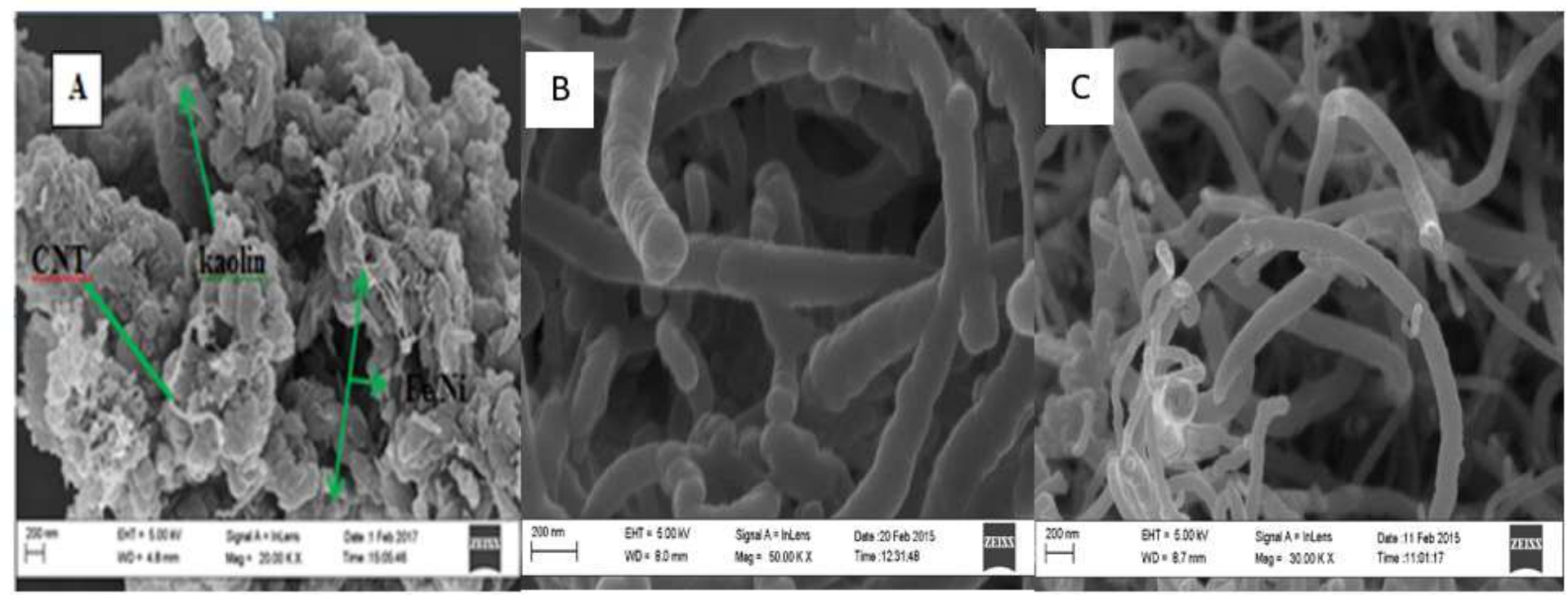

Figure 7

HRSEM patterns of (a) as-synthesized CNTs (b) P-CNTs, and (c) PEG-CNTs

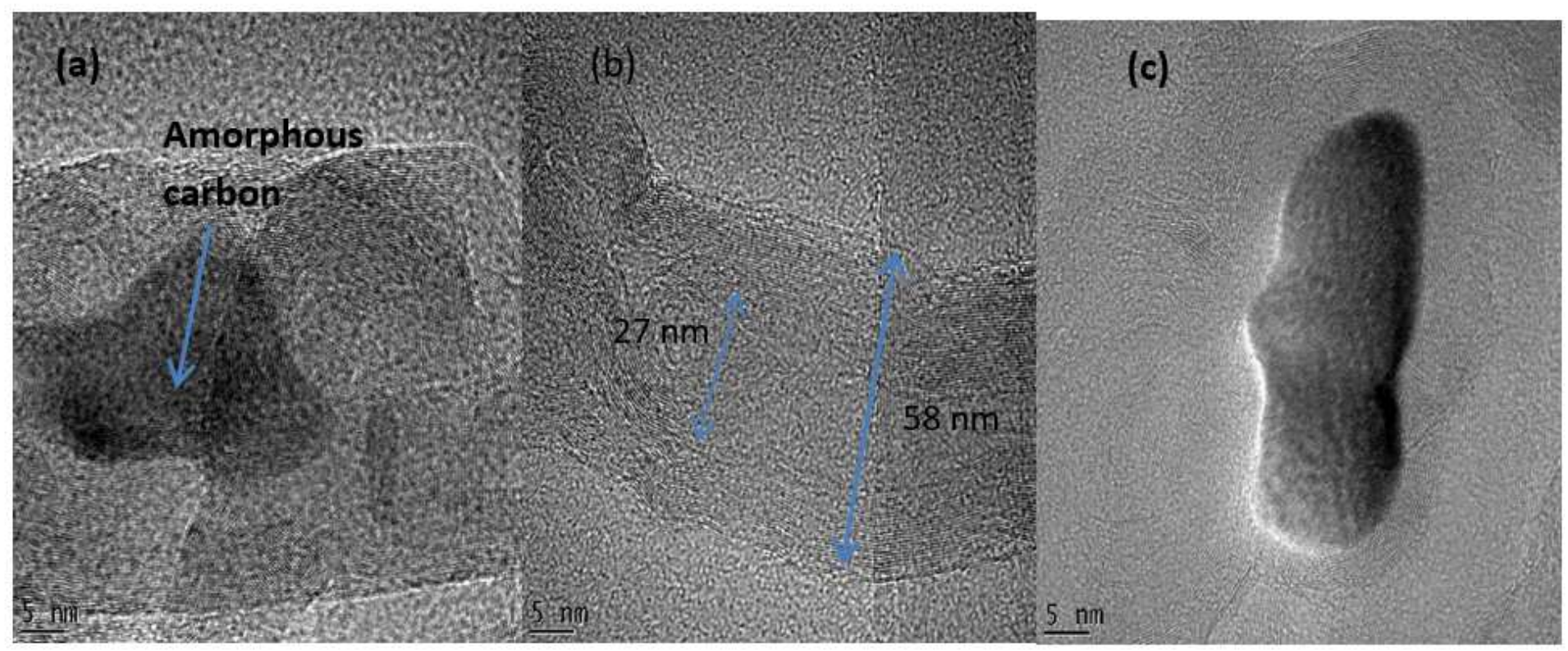

Figure 8

HRTEM patterns of (a) as-synthesized CNTs, (b) purified CNTs, (c) PEG-CNTs
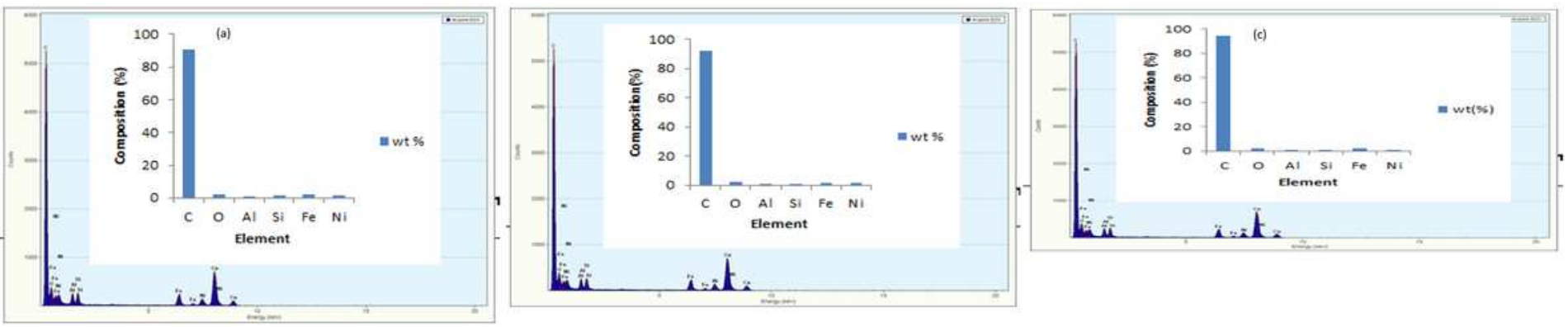
Figure 9

(a): TEM and EDS analysis of as-synthesized CNTs (b): TEM and EDS analysis of purified CNTs (c): TEM and EDS analysis of PEG-functionalized CNTs

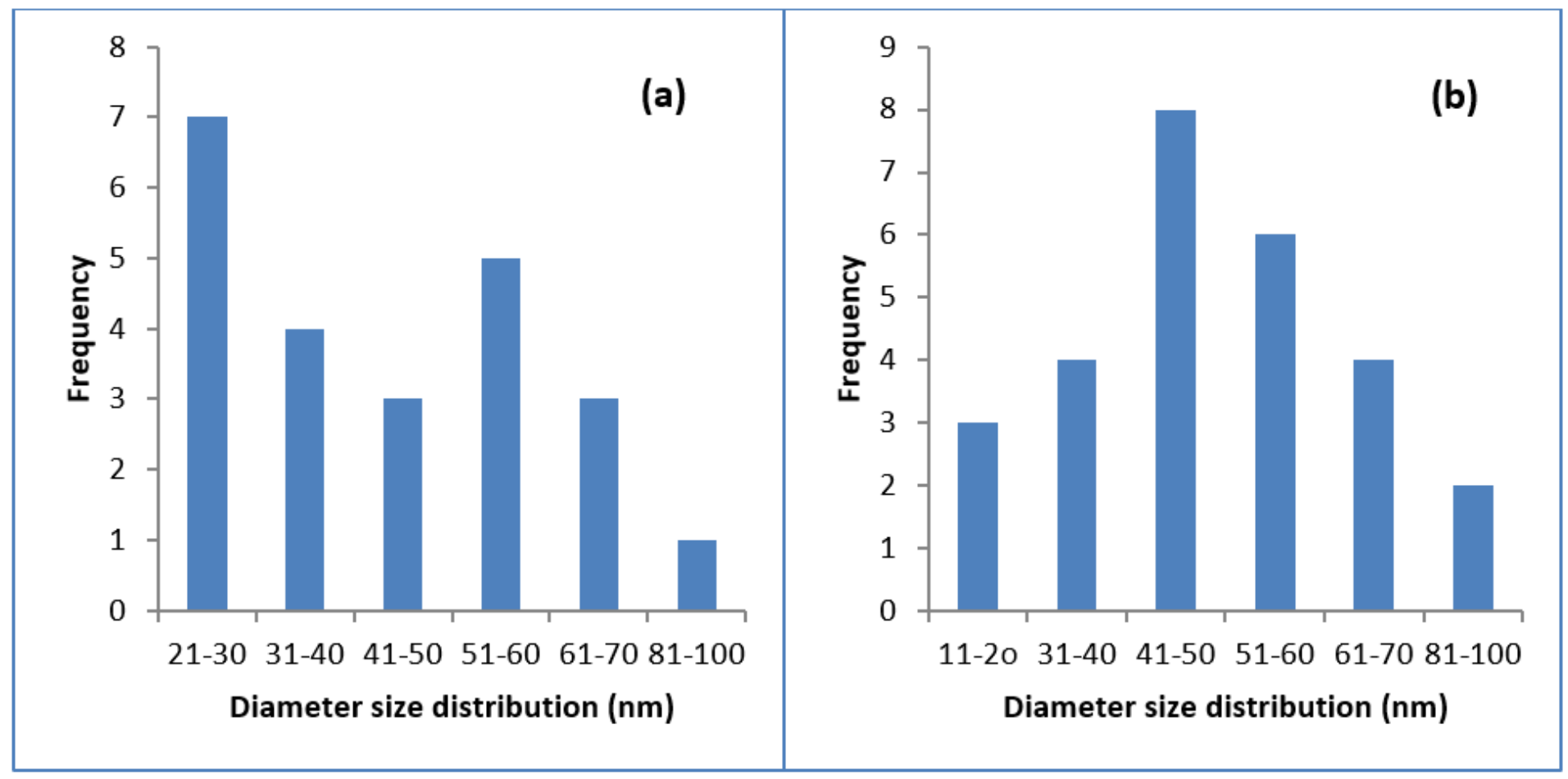

Figure 10

Diameter size distribution of (a) purified CNTs, and (b) PEG-CNTs
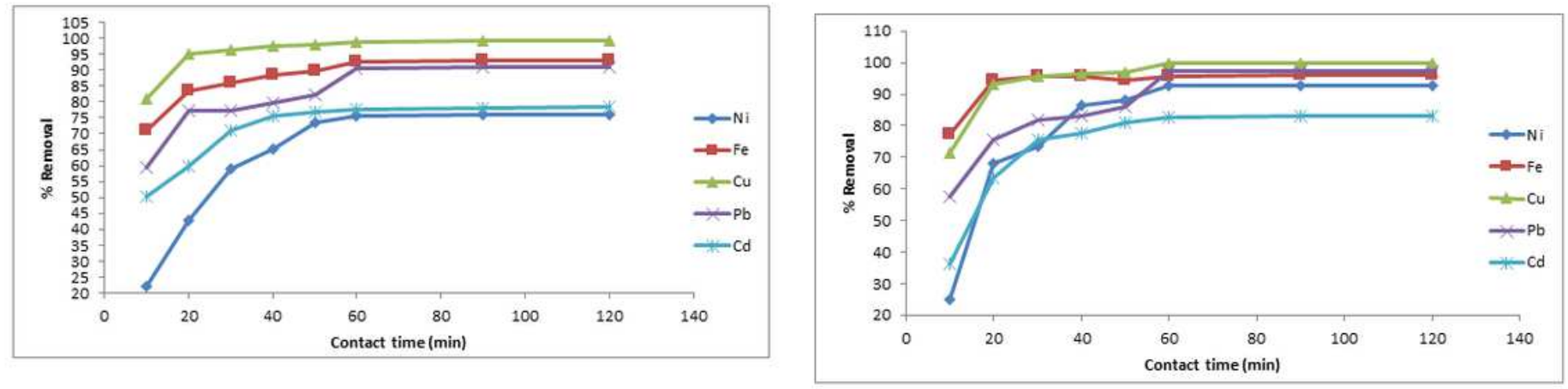

Figure 11

(a): Effect of contact time using P-CNT at nano-adsorbent dosage ( $0.1 \mathrm{~g})$, temperature ( $25 \mathrm{oC})$, agitation speed $(150 \mathrm{rpm})$ and volume of battery wastewater $(50 \mathrm{~cm} 3)$. (b): Effect of contact time on using PEGCNT at adsorbent dosage $(0.1 \mathrm{~g})$, temperature $(25 \mathrm{oC})$, agitation speed (150 rpm) and volume of wastewater $(50 \mathrm{~cm} 3)$ 

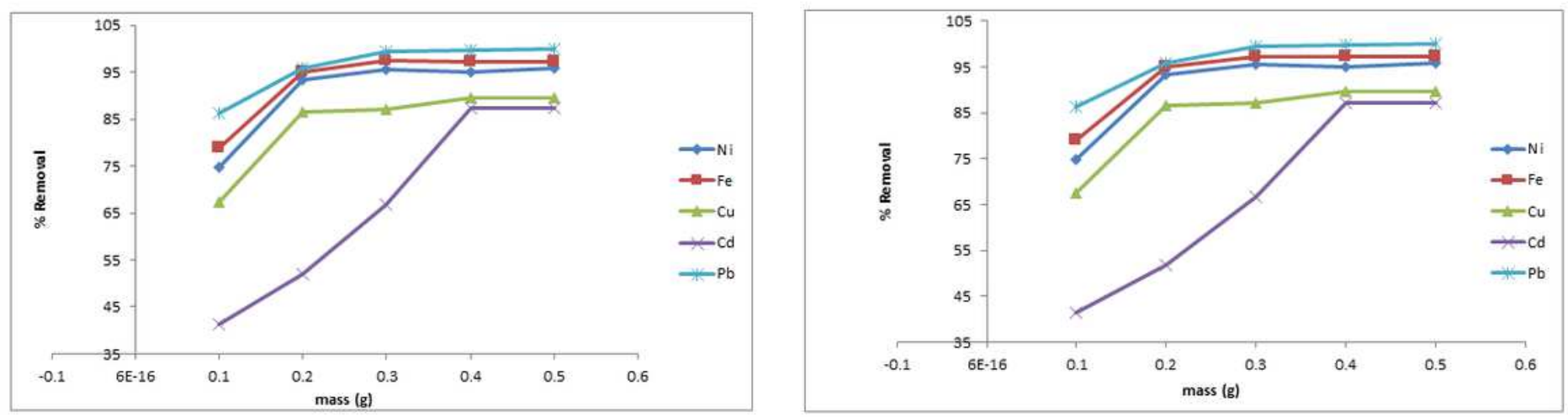

Figure 12

(a): Effect of nano-adsorbent dosage on metal ions using P-CNTs at respect contact times, agitation speed (150 rpm), temperature ( $25 \mathrm{oC})$ and volume of wastewater $(50 \mathrm{~cm} 3)(\mathrm{b})$ : Effect of nano-adsorbent dosage on metal ions using PEG-CNTs at respective contact times, agitation speed (150 rpm), temperature $(25 \mathrm{oC})$ and volume of wastewater $(50 \mathrm{~cm} 3)$
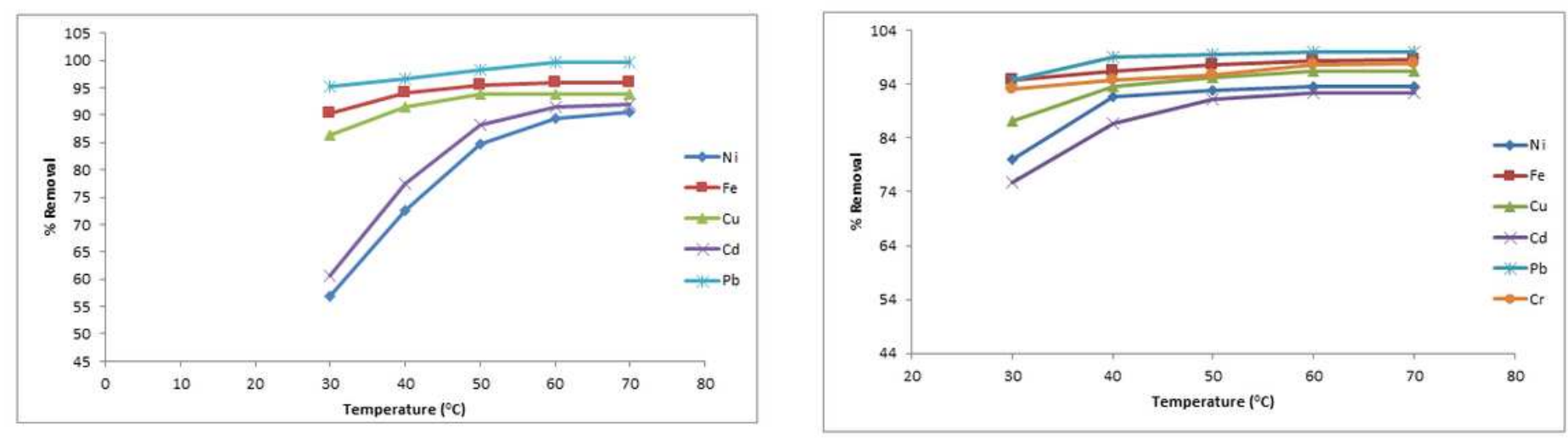

\section{Figure 13}

(a): Effect of temperature on metal ions using P-CNTs at respect contact times, adsorbent dosage (0.4 g), stirring speed $(150 \mathrm{rpm})$ and volume of wastewater $(50 \mathrm{~cm} 3)(\mathrm{b})$ : Effect of temperature on metal ions using PEG-CNTs at respect contact times, adsorbent dosage $(0.4 \mathrm{~g})$, stirring time $(150 \mathrm{rpm})$ and volume of wastewater $(50 \mathrm{~cm} 3)$ 